(C) 1991 IEEE. Personal use of this material is permitted. Permission from IEEE must be obtained for all other uses, in any current or future media, including reprinting/republishing this material for advertising or promotional purposes, creating new collective works, for resale or redistribution to servers or lists, or reuse of any copyrighted component of this work in other works.

This is an electronic copy of an article which originally was published as: Blades, M.W., Banks, P., Gill, C., Huang, D., Le Blanc, C., \& Liang, D. (1991). Application of weakly ionized plasmas for materials sampling and analysis. IEEE Transactions on Plasma Science, 19(6), 1090-1113. DOI: $10.1109 / 27.125033$

More information about IEEE Transactions on Plasma Science can be found at: http://ieeexplore.ieee.org/servlet/opac?punumber=27, and this article can be found at: http://dx.doi.org/10.1109/27.125033. 


\title{
Application of Weakly Ionized Plasmas For Materials Sampling and Analysis
}

\author{
Michael W. Blades, Peter Banks, Chris Gill, Degui Huang, Charles Le Blanc, and Dong Liang
}

(Invited Review Paper)

\begin{abstract}
The use of weakly ionized plasmas as spectroscopic sources for materials sampling and analysis is reviewed. Plasma sources currently used for this purpose include dc and ac plasmas, inductively coupled plasmas, microwave-induced plasmas, surface-wave plasmas, capacitively coupled plasmas, capacitive microwave plasmas, glow discharges, flowing afterglows, Theta pinch discharges, exploding films and wires, and laser-produced plasmas.
\end{abstract}

\section{INTRODUCTION}

$\mathbf{T}$ HE matter in the world around us is composed of the 90 or so natural elements that appear in the Periodic table. The physical and chemical properties of each piece of matter are determined by the particular combination of elements in that matter. In order to understand the behavior of matter or the interaction between different forms of matter, it is often necessary to accurately know the elemental composition of each form. For example, the physiological function of many of the elements is known. Iron, copper, zinc, manganese, and molybdenum form part of several enzymes; cobalt is an essential part of vitamin B12; magnesium is found in chlorophyll in green plants; potassium and sodium are essential in maintaining electrolyte balance; phosphorus is found in DNA and RNA; and calcium is in bones and teeth. In addition, some elements such as lead, cadmium, arsenic, nickel, and beryllium are known to be toxic to most forms of life, although this is a gross generalization, since the toxicity often depends on the concentration and chemical form (oxidation state, chelating ligands, etc.). Other elements are used medicinally; for example, lithium is used to treat manic-depressive patients. It is incumbent upon the health-care system to have means available to acquire information about the presence of these elements in patients so that their health status can be assessed.

Also, a wide variety of elements are used extensively in industrial processes (in catalysts, for example) for the fabrication of a variety of structural materials (alloys, ceramics, plastics, glasses, etc.), and for the manufacture of household and industrial products. These examples emphasize the importance of analytical determinations of trace elements in materials of various kinds. On the biological side it may be possible to predict a deficiency or toxicity and to take appropriate

Manuscript received October 3, 1989; revised August 13, 1991.

The authors are with the Department of Chemistry, University of British Columbia, Vancouver, BC V6T 1Y6, Canada.

IEEE Log Number 9104415. corrective steps. On the industrial side it is important to control the composition of a material to ensure that it has particular properties. It is also necessary to have knowledge of and control over the output of industrial waste into the environment.

During the past 130 or so years a variety of procedures for the determination of the elements in their free or uncombined form has been developed. An active branch of chemical research concerning itself with elemental analysis has evolved that includes a vast array of methodologies for elemental determinations. These have included the use of spectroscopic, electrochemical, nuclear, X-ray, and mass spectrometric methods.

Analytical atomic spectroscopy deals with the determination of elements in a sample by converting these elements to their atomic form. Samples are for the most part in the liquid or solid state; thus an important aspect of atomic spectrometry is the atomization step, the liberation of the sought-for elements (analyte elements) from the sample matrix. The agent that usually carries out this liberation process is called the spectroscopic source. For this paper the use of weakly ionized plasmas as spectroscopic sources will be reviewed.

The sample must be presented to the spectroscopic source in a form that the source can accommodate using a method that: maximizes the transport efficiency, is optimum for the particular sample type, and provides the best opportunity for obtaining the required information. An overview of the routes used to introduce a sample into a source is provided in Fig. 1. For solid samples there are basically two routes possible-the solid can be dissolved by a suitable solvent or reacted with a reagent (e.g., acids) and presented to the source in liquid form, or in some cases the geometry and mode of operation of the source are such that atoms and ions can be liberated directly from the matrix through thermal evaporation or sputtering. In this latter case, components of the plasma itself are sometimes the active agents. In some cases it may be expedient to use laser ablation or spark source sampling for solid samples. The vaporized material is then entrained in a flow of gas and transported to the plasma source. For liquids, the sample must be presented to the plasma in a form and rate that will not quench the plasma discharge. The most suitable form is as a fine spray of droplets, which is usually produced by pneumatic, ultrasonic, or some other form of nebulization. Other alternatives for liquid sample introduction include the 


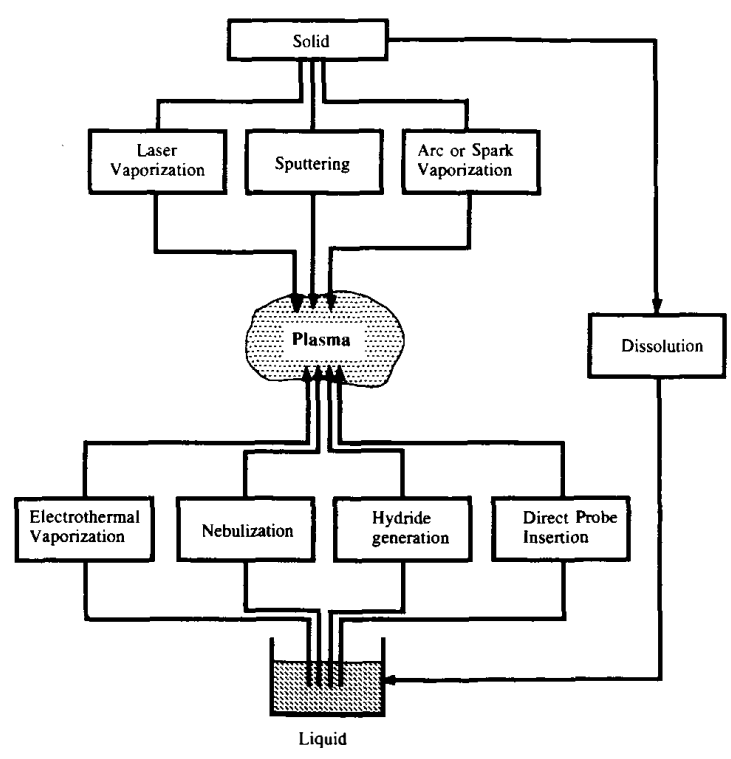

Fig. 1. Overview of methods for introducing samples into a plasma for spectrochemical determinations. Methods for the direct introduction of solids are identified on the upper part of the diagram, and methods for introducing liquids are on the lower part. Solids can also be dissolved as is shown on the right-hand side.

use of electrothermal vaporization from furnaces and metal strips, deposition of the sample on a graphite probe which is inserted directly into the plasma, and the use of hydrides.

In order to understand the role of weakly ionized plasmas in the field of atomic spectroscopy, it is useful to have an overview of the main steps involved when the elements are liberated from the sample matrix. A schematic diagram of the relevant processes is provided in Fig. 2. Once droplets are introduced into the discharge a variety of processes take place. The relatively high-temperature environment characteristic of plasma sources vaporizes the liquid, leaving particulates-a process termed desolvation. Ideally, the particulates are vaporized to form gas-phase molecules that dissociate to form free atoms. At a given temperature there will be an equilibrium between the atomic, ionic, and molecular forms of the elements present in the discharge. The purpose of the plasma discharge is to provide sufficient energy to ensure that the processes of desolvation, vaporization, and dissociation go to completion, and to maintain these conditions for a period of time sufficient for the analysis to be carried out. During the analysis step, in which the liberated atoms and/or ions are probed, the plasma is the background environment in which the measurement is carried out. The atomization step is followed by a procedure utilizing either the light absorbed or emitted by a sample to actually identify the elements present (qualitative analysis) and/or to determine the concentration of some or all of these elements in the original sample (quantitative analysis). Alternatively, ions can be extracted from the source and measured directly; for example, using mass spectrometric techniques.

A variety of techniques can be used to probe the atomic/ionic vapor cloud. These methods include atomic absorption spec-



Fig. 2. Stages in the process of converting a sample to atoms and ions.

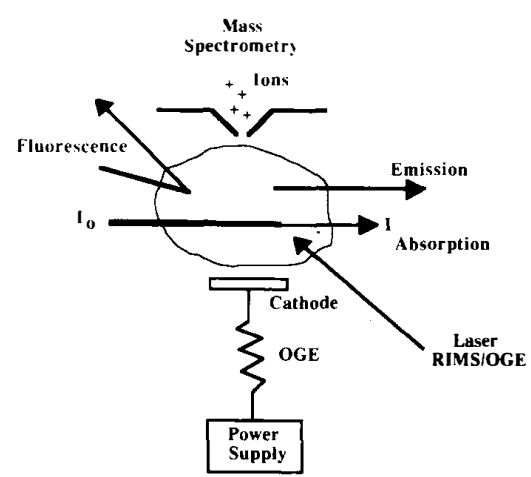

Fig. 3. Schematic diagram of various methods used to measure analyte species which have been introduced into weakly ionized plasmas.

trometry (AAS), atomic emission spectrometry (AES), atomic fluorescence spectrometry (AFS), optogalvanic spectrometry (OGS), coherent forward scattering (CFS), mass spectrometry (MS), and resonance ionization mass spectrometry (RIMS). These methods are indicated schematically in Fig. 3. It is beyond the scope of this paper to review completely the principles of each kind of spectroscopy; however, a short outline will be presented for the uninitiated.

For atomic absorption a modulated radiation source is directed through the plasma discharge. Atoms and ions in the plasma with atomic transitions that are resonant with the frequencies emitted by the radiation source will, through absorption, attenuate the beam. Normally, an amplitude-modulated hollow cathode lamp (HCL) is used as the radiation source and, since the HCL is a line and not a continuum source, the method is restricted to single-element determinations. A monochromator is used to isolate the spectral transition of interest from nonanalyte lines emitted by the HCL. The signal is demodulated to distinguish the HCL radiation from spontaneous emission from the source and the absorbance is determined. The absorbance $(A)$ is given by the Beer-Lambert law, $\log I_{o} / I=A=a b C$, where $I_{o}$ is the incident beam intensity, $I$ is the transmitted beam intensity, $a$ is an absorption 
coefficient, $b$ is the absorption pathlength, and $C$ is the concentration of the absorber.

For atomic emission, spectrometry atoms and ions in the plasma are excited by thermal or nonthermal means and emit their characteristic line spectra. Normally, the most intense emission line, the line with the largest signal-tonoise ratio $(\mathrm{S} / \mathrm{N})$ or the least spectrally interfered with line (or a line that best satisfies these criteria), is chosen for the analysis. The emission from this line is isolated using a medium- or high-resolution monochromator and detected using an appropriate photodetector. The emission intensity of the line is usually proportional to the concentration of the element in the sample so that quantitative analysis is possible. Emission spectrometry provides for the possibility of carrying out simultaneous multielement analysis, since a variety of spectral lines can be isolated and detected using a polychromator.

For atomic fluorescence spectrometry, a modulated source of radiation is directed into the plasma discharge. Atoms and ions in the plasma that have atomic transitions resonant with the frequencies emitted by the radiation source are excited and emission from the photoexcited species is measured. A monochromator or filter is used to isolate the spectral transition of interest. The signal is demodulated to distinguish the fluorescence radiation from spontaneous emission from the source. As a first approximation, at relatively low concentrations the fluorescence intensity is directly proportional to the concentration of the element in solution so that quantitative analysis can be carried out.

For optogalvanic spectrometry, a pair of electrodes with a high voltage bias is placed around the plasma and the current flow produced from photoionized atoms is measured. This method has been very useful for analytical determinations in flame sources; however, since plasmas are ionized gases background currents are high, and this feature limits the sensitivity for these sources.

For plasma source mass spectrometry, ions are extracted from the plasma through a sampling orifice and analyzed on the basis of their mass-to-charge ratio using a conventional mass spectrometer.

By far the most popular method for carrying-out spectrochemical analysis using plasma sources is emission spectrometry. The technique does not require primary sources and is inherently capable of simultaneous multielement determinations. The instrumentation is relatively simple and the observation of emission from the source does not affect the operation or characteristics of the source directly. Although atomic absorption using flames or furnaces is popular, the method has had only limited utility when used with plasma sources. During the 1980's, plasma source mass spectrometry emerged as a very powerful analytical method. It provides the capability of essentially simultaneous multielement determinations, with the added benefit of the ability to determine isotopic abundances.

Many different kinds of plasma have been utilized as sources for spectrochemical analysis. The intent of the authors is to discuss the major sources and to provide information on the historical development, the means of plasma generation, some basic characteristics, and the method of application
TABLE I

Characteristics of an Ideal Plasma Source

\begin{tabular}{ll}
\hline 1. & Complete quantitative conversion of sample atoms (ions) \\
2. & Excitation energy easily controlled \\
3. & Ability to excite all elements (AES) \\
4. & Inert chemical environment \\
5. & Low background \\
6. & Ability to accept solids, liquids, or gases directly \\
7. & Plasma conditions independent of sample loading and composition \\
8. & Plasma conditions reproducible from sample to sample \\
9. & Short and long term stability \\
10. & Low purchase and operating costs \\
11. & Ease of operation and potential for automation \\
12. & Plasma physics and chemistry completely understood \\
13. & Separate control of atomization and excitation (ionization) \\
\hline
\end{tabular}

to analytical problem-solving. In general, we can define the characteristics of what we might call the ideal plasma source. These characteristics are summarized in Table I. Plasma sources currently in use as spectroscopic sources include dc (Arc) and ac (Spark) plasmas, inductively coupled plasmas (ICP), microwave-induced plasmas (MIP), surfacewave plasmas (Surfatron), capacitively coupled plasmas (CCP), capacitive microwave plasmas (CMP), glow discharges (GD), flowing afterglows, Theta-pinch discharges, exploding films and wires, and laser-produced plasmas. The reason for the variety of plasmas used for chemical analys is is that no one plasma satisfies all of the ideal characteristics outlined in Table I. With respect to this table, each kind of plasma source has strengths and weaknesses; one goal of research into the use of plasma sources for chemical analysis is to develop a plasma source that incorporates as many of the features outlined in Table I as possible.

When the plasma source itself is coupled with a spectroscopic method a new set of requirements emerge that relate to the performance of the combination. These features are dependent on the characteristics of both the source and the spectroscopic method. However, it is usually the case that the source characteristics primarily dictate the strengths and weaknesses of a particular method. Important figures of merit for a spectrochemical method are outlined in Table II. Multielement capability is a consequence of the measurement technique used and is important, since it provides the ability to obtain a maximum amount of information on each sample in the shortest possible time and with the minimum amount of sample. The detection limit is defined as the analyte concentration that provides a signal-to-noise ration $(\mathrm{S} / \mathrm{N})$ of 3 where the noise is the standard deviation of the background. A low detection limit enables the analytical method to be used for trace determinations. Atomic spectroscopy is currently capable of providing a detection limit in the $\mathrm{pg} / \mathrm{mL}$ (partsper-trillion) to $\mathrm{ng} / \mathrm{mL}$ (parts-per-billion) range, depending on the element and method. Selectivity is normally a function of the quality of the measurement system and is a measure of the ability of the method to distinguish the presence of one element in a mixture of elements. Accuracy and precision are usually determined by the stability of the source, and are a measure of the confidence the analyst has in the analytical determination. Large linear dynamic range provides the possibility of determining elements over a wide concentration range 
TABLE II

IMPORTANT FIGURES OF MERIT FOR AN ANALYTICAL METHOD

\begin{tabular}{ll}
\hline 1. & Simultaneous multielement capability \\
2. & Low limit of detection \\
3. & High selectivity to elements of interest \\
4. & Good accuracy and precision \\
5. & Applicable over a wide concentration range (large dynamic range) \\
6. & Freedom from chemical and spectral interferences \\
7. & Can accomodate gas, liquid, or solid samples easily \\
8. & High sample throughput rate \\
9. & Ease of automatation \\
\hline
\end{tabular}

without dilution, and is determined by the physics of the source and the intrinsic dynamic range of the detection system. The ability to accommodate a variety of sample types is usually a consequence of the operating principles and geometry of the source. The sample throughput rate is a measure of the amount of time it takes for the analysis to be carried out on each sample. The limitation to sample throughput is related to the accuracy and precision required for the measurement and characteristics of the sample-introduction system.

This review will begin with the two most important types of plasma source from a commercial standpoint-the inductively coupled plasma and the dc plasma. We will then examine the microwave-induced plasmas, glow discharge plasmas, capacitively coupled plasmas, and transient plasmas in no particular order.

\section{Inductively Coupled Plasma (ICP)}

The inductively coupled plasma was first described by Babat in 1947 [1]; however, very little appeared after that until 1961, when Reed [2] published a paper describing an ICP operating at atmospheric pressure, supported by a flow of argon gas. The plasma torch consisted of a quartz tube, open at one end, that was supplied with a flow of argon at the other. A five-turn water-cooled induction coil was wrapped around the quartz tube near the open end and RF power up to $10 \mathrm{~kW}$ at $4 \mathrm{MHz}$ was delivered to the coil. The plasma was initiated by inserting a graphite rod into the RF field, concentric with the coil. The graphite rod was inductively heated and thermionic emission of electrons initiated the plasma discharge. Reed also described a means of centering the ICP discharge in the quartz tube using a technique called vortex stabilization, in which the support gas was introduced into the torch tangentially, causing a helical flow up along the tube walls. This acted to center the plasma, recirculated some of the plasma gas in the load coil area, and cooled the quartz tube to prevent melting. The ICP described by Reed was used to grow single crystals of refractory oxides such as sapphire and zirconia.

Closely following Reed's publication, Greenfield et al. [3] and Wendt and Fassel [4] described the use of a similar torch configuration in which the plasma was used as a source for analytical atomic emission spectrometry (ICP-AES). During the ten years that followed, the analytical characteristics and capabilities of the ICP as an emission source for simultaneous multielement analysis were firmly established by a number of research groups. In 1973 the first commercial ICP system was put on the market, and since that time this plasma has emerged as the dominant method for multielement analysis of liquids. The phenomenal growth of the ICP is due to the fact that it is a potent atomization and excitation source and thus has inherent simultaneous multielement analysis capability, is relatively free from chemical interferences, has large linear dynamic range, and detection limits which are in the 1-20 $\mathrm{ng} / \mathrm{mL}$ range for many elements. In addition to its use as an emission source, the ICP has also been used as an atomization cell for elemental determinations by atomic fluorescence (ICPAFS) and has been successfully marketed as an ion source for plasma source mass spectrometry (ICP-MS). Much of the innovative development work for ICP-AES, ICP-AFS, and ICP-MS was carried out in the laboratory of Prof. V. Fassel at Ames, Iowa, and a personal account of these developments has been published [5]. Recently, two excellent comprehensive texts on the topic of analytical applications of the ICP have been published [6], [7]. Also, a monthly newsletter called the ICP Information Newsletter is published by Prof. R. Barnes at the University of Massachusetts.

A schematic diagram outlining the important features of a typical ICP torch is provided in Fig. 4. It consists of three concentric quartz tubes. The plasma is sustained by the support gas (generally $\mathrm{Ar}$, but $\mathrm{N}_{2}, \mathrm{O}_{2}, \mathrm{He}$, and air have been used [8]) that flows in a helical pattern in the small $(0.35-1 \mathrm{~mm})$ annular space between the outer and intermediate tubes. Normally, coolant-gas flows in the range of $10-15 \mathrm{~L} / \mathrm{min}$ are used; however, optimized, "low-flow" torches have been developed that will operate at gas flows as low as $4 \mathrm{~L} / \mathrm{min}$ (see [7, chap. 4]). A water-cooled, 2-5 turn, copper-load coil encircling the outer tube near the outlet end of the torch is used to couple $\mathrm{RF}$ power to the support gas. RF power supplies generally use either free running (TATG, Colpitts, Huth-Kuhn, tuned line) or crystal-controlled (Pierce) oscillators and operate at frequencies between 7 and $148 \mathrm{MHz}$. The most common operating frequencies are 27.12 and $40.68 \mathrm{MHz}$. A Tesla coil terminating near the base of the torch is initially used to ionize the support gas. The resulting electrons, which are transported to the load coil area, are accelerated in the magnetic field and collide with neutral Ar, causing further ionization. After initiation the plasma reaches a steady state in which the ionization process is balanced by recombination and ion loss from transport, and the plasma is sustained by continuous application of the RF power. The RF field is attenuated by the plasma such that the field strength is lower at the center of the plasma. This produces an annular plasma in which the ion and electron density is lower along the discharge axis. This facilitates the introduction of sample into the plasma. A small flow $(0-1 \mathrm{~L} / \mathrm{min})$ of intermediate gas, often introduced tangentially between the central and intermediate tubes is used to keep the plasma from coming into contact with the quartz tubes.

Usually, samples are introduced into the plasma as aerosols through the central quartz tube using an aerosol carrier gas flow between 0.4 and $1 \mathrm{~L} / \mathrm{min}$. The aerosol gas flow forms a channel that runs the length of the plasma discharge. As the aerosol progresses up the channel it mixes with hot plasma gas, and the processes of desolvation, vaporization, dissociation, excitation, and ionization take place. Emission from analyte species can be observed in a zone between 8 and $20 \mathrm{~mm}$ above the load coil. This zone is often call the normal analytical zone (NAZ). 


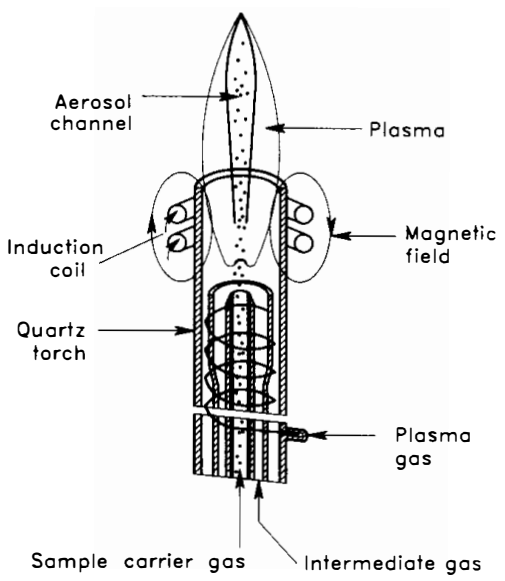

Fig. 4. Schematic diagram of an ICP torch and plasma discharge.

\section{A. Sample Introduction}

A variety of means have been utilized to introduce samples into the plasma discharge. Liquids can be converted to an aerosol using pneumatic crossed flow or concentric (e. g., Meinhard) nebulizers, ultrasonic nebulizers, or glass frit nebulizers. Large droplets that might quench the plasma are removed from the aerosol stream using a "spray chamber," which filters the aerosol by gravitation and impaction, allowing only droplets in the $1-10-\mu \mathrm{m}$ range to enter the plasma. About $0.5-2 \mathrm{~mL}$ of liquid is required for each analysis. A schematic diagram showing a concentric nebulizer, spray chamber, plasma torch combination is provided in Fig. 5. Aerosol generation and transport processes have been reviewed by Browner and Boorn [9], [10].

Application of the ICP for elemental analysis has not been restricted to continuous sample introduction of liquids. A diagram summarizing the various modes of sample introduction is provided in Fig. 6. For the determination of the elements $\mathrm{As}, \mathrm{Pb}, \mathrm{Se}, \mathrm{Bi}, \mathrm{Ge}, \mathrm{Sb}, \mathrm{Sn}$, and $\mathrm{Te}$, sodium borohydride $\left(\mathrm{NaBH}_{4}\right)$ can be used to convert the dissolved elements to the volatile hydride gas that is swept into the plasma [11]. For small volumes of liquid samples $(10-50 \mu \mathrm{L})$, electrothermal vaporization using electrically heated graphite tubes, tantalum strips, or microarcs has been utilized. The atomic vapor produced is swept into the plasma, generating a transient emission signal. Attempts to atomize solids for introduction into the ICP have included the use of electrical arcs and sparks and laser ablation. Small particulates have been introduced using fluidized beds and swirl cups, and nebulized slurries. Also, the ICP has been used as a detector for gas-, liquid-, and supercritical-fluid chromatographies in which the effluent of the chromatograph is introduced using an appropriate interface. For details on these sample introduction methods the reader should consult [6] and [7].

\section{B. Plasma Characteristics}

The ICP has been studied extensively from a fundamental standpoint. For Ar, the plasma is about $1 \%$ ionized and has

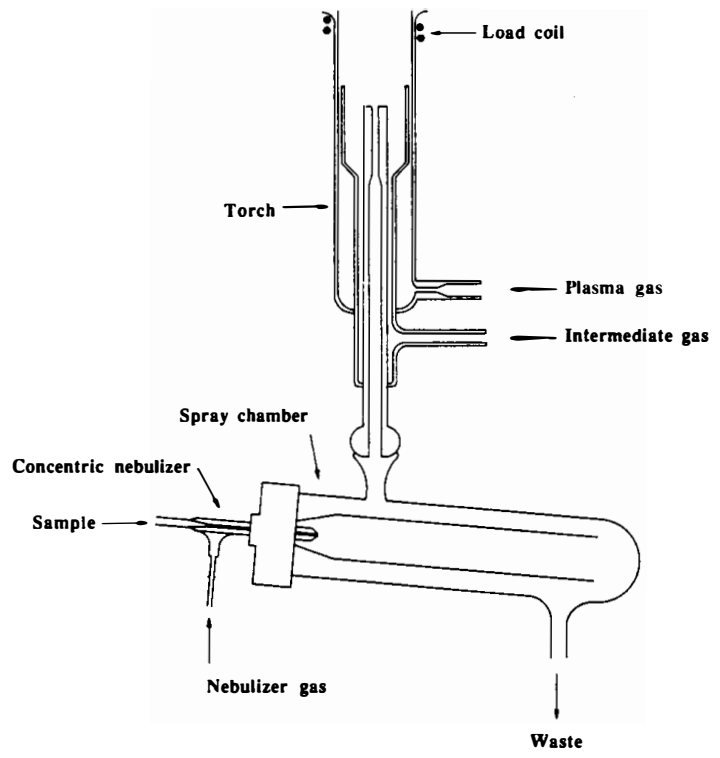

Fig. 5. Schematic diagram of a typical nebulizer, spray chamber, plasma torch assembly. Liquid sample is nebulized into the spray chamber. Large droplets go to the waste outlet. Small droplets are carried along with the nebulizer gas into the plasma discharge.

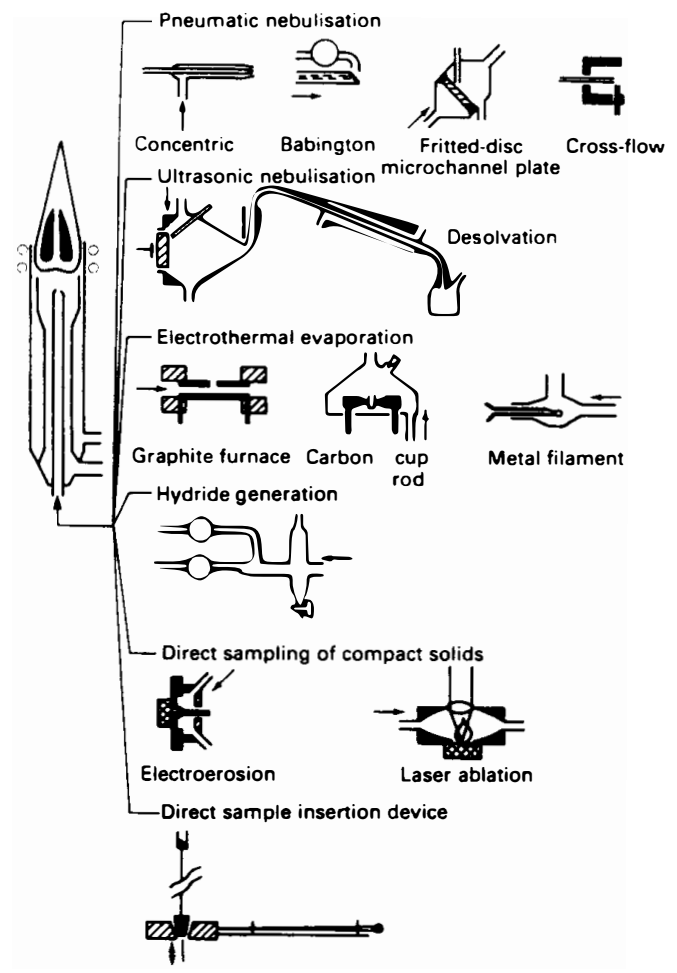

Fig. 6. Overview of routes used for sample introduction in conjunction with ICP's. (Reprinted with permission from G. Tolg, Analyst, vol. 112, p. 365, 1987.)

electron number densities in the $5 \times 10^{14}-5 \times 10^{15} \mathrm{e} / \mathrm{cm}^{3}$ [12] range, with the corresponding Ar ionization temperature 


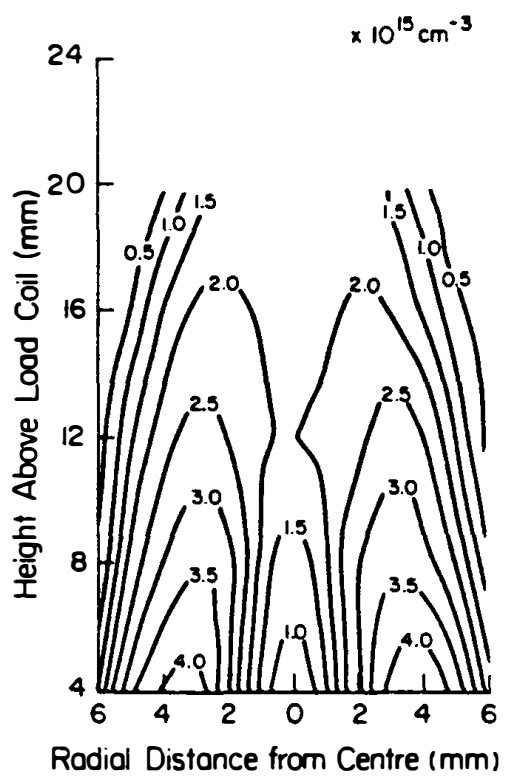

Fig. 7. Radial distribution of electron number density distribution in an RF ICP operating at $1.25-\mathrm{kW}$ forward power. Isopleths are in units of $10^{15} \mathrm{e}^{-} \mathrm{cm}^{-3}$. Electron density values were measured using $\mathrm{H}_{3}$ line broadening. (Reprinted with permission from [12].)

in the range of $7300-8900 \mathrm{~K}$. A pictorial representation of the spatial distribution of electron number density at an $\mathrm{RF}$ input power of $1.25 \mathrm{~kW}$ is provided in Fig. 7. The vertical axis for this plot is height above the induction coil, and the horizontal axis is the radial coordinate. The electron number density exhibits off-axis maxima created as a result of cooling of the aerosol channel by introduction of the aerosol. Analyte that is introduced into the plasma is readily converted to atoms and ions. Excitation temperatures are in the range of 5000 to $8000 \mathrm{~K}$ in argon, depending on the element and the method of measurement [12], indicating that the ICP is an excellent source for populating excited states: hence its extensive use in emission spectrometry.

The degree of ionization is between 70 to $99 \%$ for most of the elements in the periodic table, depending on the ionization energy, which also makes the ICP an excellent source for analytical mass spectrometry. This high degree of ionization also means that many of the most sensitive analytical emission lines are ionic. Chemical interference effects due to the formation of molecular species such as refractory oxides are minimal, because the high-temperature environment can dissociate even very stable molecular species. Self-absorption, a process whereby light emitted by species near the plasma axis is absorbed by like species near the plasma boundary, is minimized, since the analyte is confined to a small region along the plasma axis. This characteristic yields a large linear dynamic range for elemental determinations.

\section{Applications}

ICP optical emission spectrometry (ICP-OES) has been applied analytically for the determination of the elemental

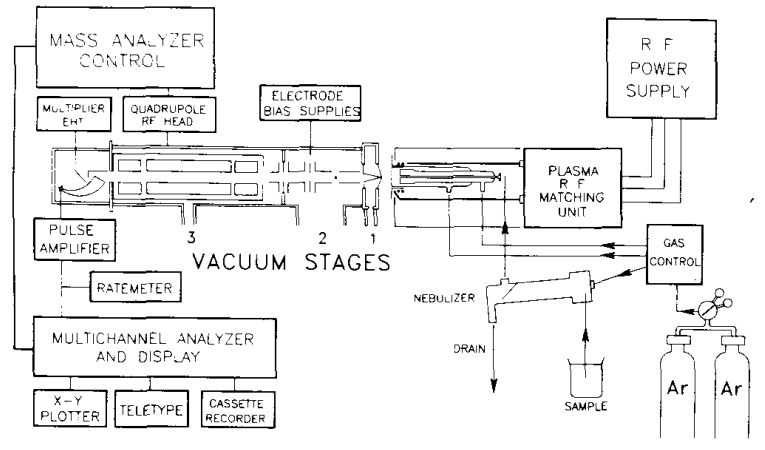

Fig. 8. Schematic diagram of a typical ICP mass spectrometer. (Reprinted with permission from A. R. Date, Trends in Analytical Chemistry, vol. 2, p. 225, 1983.)

composition of a variety of sample types. It is used extensively for samples of geological, agricultural, biological, clinical, petrochemical, and environmental origin. Samples are usually dissolved in an agent such as a mixture of hydrochloric acid, perchloric acid, or nitric acid, such that the matrix is destroyed and the trace elements liberated into an acidified aqueous solution. Petroleum samples can be aspirated directly after dilution with a suitable organic solvent such as xylene or methyl isobutyl ketone. The liquid is nebulized using one of the methods already discussed, and either an emission polychromator (direct reader) or a sequential slew-scan monochromator is used to disperse the radiation and isolate the spectral analysis lines of interest. The emission intensity for each line is measured and the concentration is determined by interpolation from a calibration curve.

\section{Inductively Coupled Plasma Mass Spectrometry}

As has already been mentioned, the ICP has proven to be useful as a source for mass spectrometry. The early development work on this technique was carried out by Fassel et al. [13], [14], Douglas et al. [15], and Date and Gray [16]. ICPMS provides capabilities that are unique in solution analysis by analytical atomic spectroscopy. In general, detection limits are in the range of 0.001 to $1 \mathrm{ng} / \mathrm{mL}$ for most elements. Plasma-source mass spectra are considerably simpler than the corresponding optical spectra which reduce the possibility of spectral interelement interferences. Also, mass spectrometry inherently provides access to isotopic abundance information in a relatively straightforward manner. As a routine method for qualitative and quantitative multielement analysis combined with a low detection limit, this method is unsurpassed. Several good reviews discussing ICP-MS have been published [6], [7], [17]-[19].

A schematic diagram of a typical ICP-MS instrument is provided in Fig. 8. Sample ions created in the plasma are extracted through orifices in an extraction-cone/skimmer-cone combination, each of which has an orifice diameter of about $1 \mathrm{~mm}$. Sampling cones are constructed of nickel, platinum, or copper and are water-cooled. The ions are passed through a series of ion lenses and around a photon stop, after which they enter a quadrupole mass filter. The quadrupole mass 


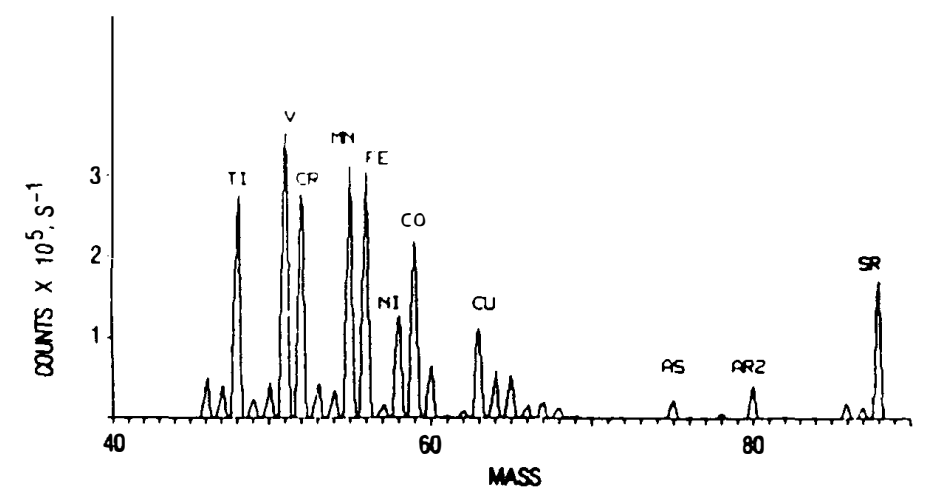

Fig. 9. A typical solution mass spectrum obtained from an aqueous sample containing $\mathrm{Ti}, \mathrm{V}, \mathrm{Cr}, \mathrm{Mn}, \mathrm{Fe}, \mathrm{Ni}, \mathrm{Co}, \mathrm{Cu}, \mathrm{As}$, and $\mathrm{Sr}$ at $10 \mu \mathrm{g} / \mathrm{mL}$ each. (Reprinted with permission from G. H. Horlick, in Inductively Coupled Plasmas in Analytical Spectrometry, 1987.)

filter separates the elements on the basis of the mass-to-charge ratio $(\mathrm{M} / \mathrm{Z})$, and the ions are sequentially detected using a channel electron multiplier or similar charged-particle detector. A "typical" mass spectrum for a multielement mixture is provided in Fig. 9.

ICP-MS is subject to both isobaric (spectral) interferences from metal oxide, halide, and argide ions, and interelement interferences that originate in the ion-optics of the mass spectrometer [20]-[22].

Refinements to the source and instrumentation have continued to improve its performance, and areas of application are rapidly increasing. ICP-MS can make use of all of the sample introduction methods that have been used successfully with ICP-OES.

\section{E. Inductively Coupled Plasma Atomic Fluorescence Spectrometry}

Baird Corporation markets an ICP-based instrument for simultaneous multielement determinations based on the principle of atomic fluorescence spectrometry (ICP-AFS) [23], [24]. A schematic diagram of the instrumentation is provided in Fig. 10. For this instrument, 12 amplitude-modulated hollow cathode lamps are arranged in a circle around the ICP discharge to excite atomic states of the elements of interest. The use of HCL's ensures good spectral selectivity. Atomic fluorescence is detected using a lens-filter combination in which the spectral bandpass of the filter overlaps with the fluorescence emission wavelength. Detection limits for ICP-AFS are in the sub$\mathrm{ng} / \mathrm{mL}$ range for many elements, and it has been used for analytical determinations for a variety of sample types.

The ICP has proven to be a powerful and versatile source for atomic spectroscopy during the past two decades and will likely remain so for some time.

\section{Direct-CurRent Plasma (DCP)}

Direct-current (dc) arcs and alternating-current (ac) sparks were developed specifically as emission sources for the analysis of electrically conducting solids. These devices consist of two electrodes, between which an electric discharge is struck.

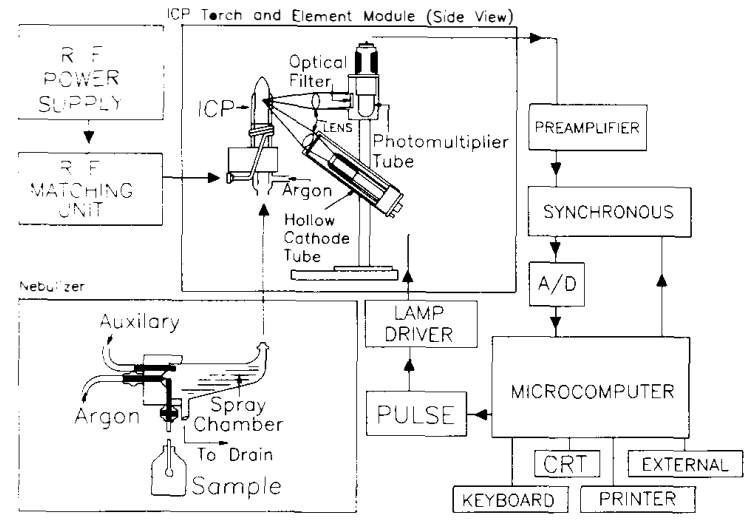

Fig. 10. Schematic diagram of the Baird ICP-AFS instrument. Twelve element modules surround the ICP torch in a circle. (Reprinted with permission from J. D. Winefordner and N. Omenetto in Inductively Coupled Plasmas in Analytical Spectrometry, 1987.)

The arc and spark differ in the duration and type of the applied current. While the spark usually results from a briefly applied ac current, the arc results from a dc current that may be sustained for several minutes. The sample, which may be the electrode itself or a solid placed upon it, is vaporized through the action of the discharge. These sources have somewhat limited utility for the analysis of liquids and gases, which restricts their usefulness in routine chemical analysis. The introduction of the dc plasma arc devices relaxed this restriction. They provided a convenient means for the spectrochemical emission analysis of liquids and gases, providing a technique for the analysis of sample solutions.

Plasma-arc devices were first introduced for solution spectrochemical analysis in 1959 by Margoshes and Scribner [25] and Korolev and Vainshtein [26]. Margoshes and Scribner's device, a "plasma jet," used two graphite-disk electrodes (Fig. 11) as the anode and cathode. Argon was used as the nebulizer gas, and helium served as a coolant gas that was introduced tangentially into the plasma chamber. This plasma jet was operated at currents of 10-15 A from a standard dc power supply. The plasma consisted of a conical "flame" 


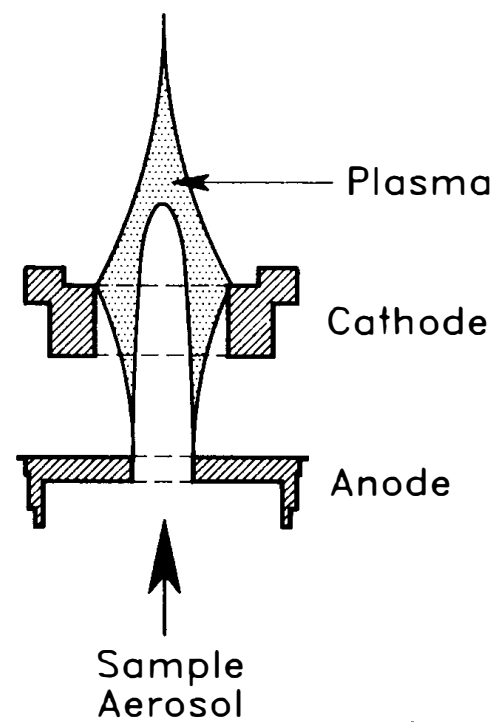

Fig. 11. Electrode configuration of the dc plasma developed by Margoshes and Scribner [25].

and a current-carrying streamer in contact with the flame and cathode. The contact point of this streamer to the cathode wandered and caused the plasma flame to move around. Korolev and Vainshtein's "plasmatron" was similar in design and used nitrogen as plasma gas.

Owen [27] showed that an external cathode improved the stability of the plasma jet, and Scribner and Margoshes [28] modified their design accordingly. Their improved model, the gas-stabilized arc, contained an external tungsten cathode. The original ring cathode became a control ring and had its own potential. Elliott [29] described a device, similar to Owen's gas stabilized arc, that was offered commercially as the Spectrametrics, Inc. SpectraJet. Several studies on this and similar designs soon followed, which included characterization and optimization of the operating parameters and application studies. In 1970 Valente and Schrenk [30] designed and characterized a novel two-electrode "dc-arc plasmajet," and Marinkovic and Vickers [31] designed a dc plasma with a similar operating configuration. This design was characterized for emission spectrometric analysis by Rippetoe et al. [32].

The Spectrametrics, Inc. SpectraJet II was similar to Valente and Schrenk's plasmajet. This design, described by Keirs and Vickers [33], also contained two electrodes, with the cathode positioned off the central axis. The angle formed by the two electrodes was approximately $90^{\circ}$, creating an inverted Vshaped plasma. The aerosol sample was introduced via a separate sample tube positioned under the inverted V. Coleman et al. [34] found that the detection limits for chromium, copper, and magnesium emission could be improved by a factor of approximately 2 by changing the angle to $45^{\circ}$, presumably the result of a reduction in spectral background.

Fig. 12 is a schematic diagram of the SpectraJet III, which was introduced by Spectrametrics, Inc. and is currently marketed by ARL-Fisions. This configuration, which has proven

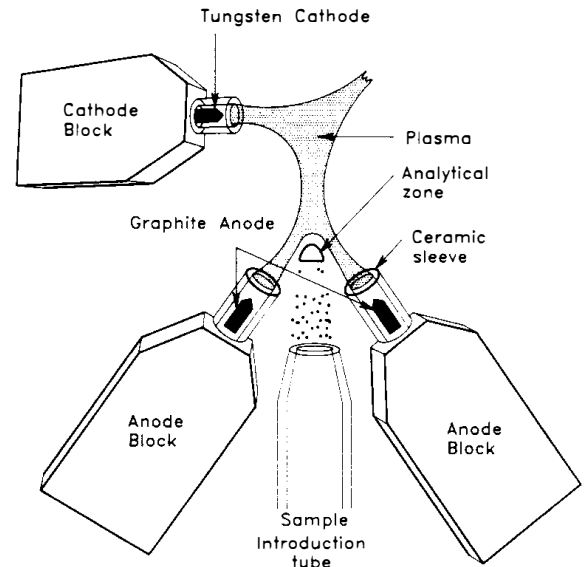

Fig. 12. Electrode configuration of the SpectraJet III dc plasma. The plasma is formed between the two anodes at the bottom and the cathode at the top. Sample is introduced into the plasma in the form of an aerosol through the sample introduction tube. Emission is observed from the analytical zone.

to be the most successful implementation, consists of two graphite anodes which form an $\sim 35^{\circ}$ angle, with a tungsten cathode positioned above these anodes. As a result of the relative electrode positions, the plasma has an inverted $\mathrm{Y}$ shape, as can be seen in Fig. 12. This creates an observation or analytical zone, characterized by a relatively high signal-to-background (S/B) ratio, slightly below the center of the inverted Y. This region has a cross-sectional area of approximately $0.25 \mathrm{~mm}^{2}$. The exact position of this zone is determined by the argon-gas flows around the anodes, and also by the gas flow through the aerosol delivery channel.

\section{A. Plasma Characteristics}

Electron density measurements in the three-electrode DCP typically yield values in the $10^{15}-10^{16} \mathrm{~cm}^{-3}$ range [35]-[37], depending on whether the measurement is made at the currentcarrying core or at or near the analytical zone. A pictorial representation of the electron number density distribution in the three-electrode DCP is provided in Fig. 13 [35], [37]. Electron number density is highest in the current-carrying core along the axis of the anode jets. In the analytical zone the electron number density is in the range of $0.5-3 \times 10^{15} \mathrm{~cm}^{-1}$, with a very steep gradient from bottom to top. The DCP exhibits a thermal pinch arising from the flow of cool argon issuing from the anode sleeves, and from the aerosol gas flow around the spectroscopic viewing zone [35]. In the analytical zone, excitation temperatures range from 5100 to $7900 \mathrm{~K}$ [38], [39].

Although the temperatures and electron number densities are comparable to those found in the ICP, the DCP is not as effective at exciting and ionizing elements introduced in the sample aerosol stream. The reason for this is related to the short analyte residence time and the inability of the analyte stream to penetrate the current-carrying plasma core. The analyte takes a path around the plasma, and excitation takes place at a boundary region adjacent to the high-density-plasma 


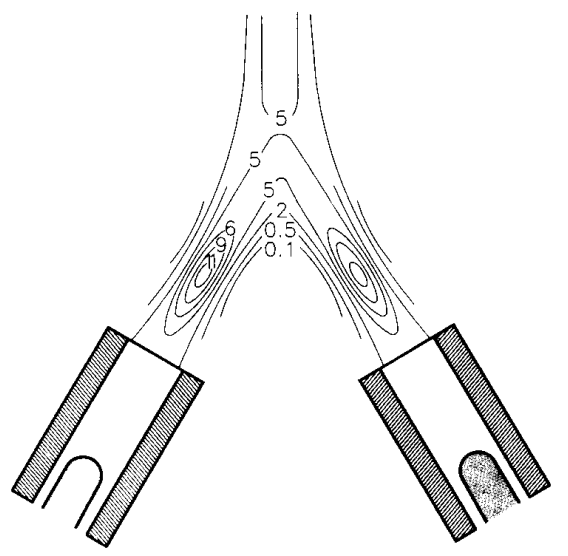

Fig. 13. Electron number density distribution in a three-electrode DCP. Contour lines are in units of $10^{15} \mathrm{~cm}^{-3}$. (Adapted from Zander and Miller [35] and Blades and Lee [37].)

region [29], [40]. Analyte emission line intensities in the DCP have been shown to be sensitive to the presence of easily ionized elements present in sample matrices. Both emission suppression and enhancement is observed, depending on the element, ionization stage, and spatial position. The effect appears to be due to a combination of ionization suppression and modification of the plasma-excitation conditions [40].

\section{B. Applications}

The three-electrode dc plasma has attracted more interest than previous DCP designs, mainly due to its success as an atomic emission source. It is marketed in conjunction with a high-resolution echelle-based polychromator which provides a very compact elemental analysis system at a relatively low cost. Detection limits are in the $10-100 \mathrm{ng} / \mathrm{mL}$ range for many elements, which are approximately an order of magnitude higher than those obtained for ICP-AES. The DCP is much more susceptible to self-absorption compared with the ICP, and three to four orders of magnitude is usual for its dynamic range.

Despite these limitations, the three-electrode DCP is a versatile source and has been used to determine trace metals in organic as well as aqueous solutions. The DCP is perhaps best known for its robustness, since sustained plasma operation with total dissolved solids as high as $40-45 \%$ in sample solutions is possible. Areas of application are similar to those for which the ICP is used, although with the benefit that the plasma source is less expensive. The DCP has not been used with any degree of success as an MS, AFS, or AAS source.

\section{Microwave-Induced Plasmas}

\section{A. MIP's}

A microwave-induced plasma (MIP) is usually an electrodeless discharge generated in a glass or quartz tube, having an inner diameter on the order of a few millimeters to a few centimeters. Initially, MIP's used a single-electrode to couple

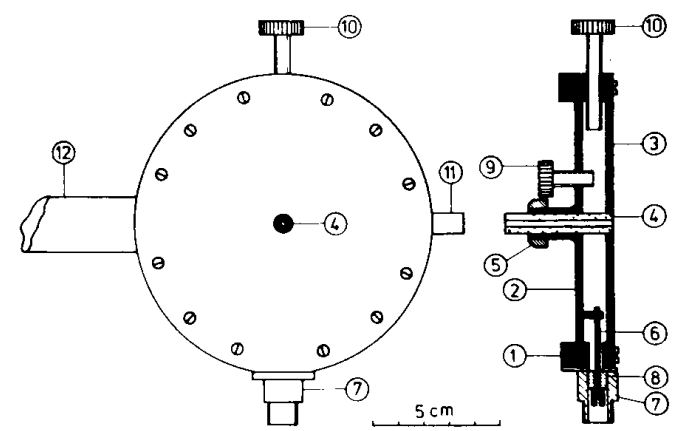

Fig. 14. Schematic diagram of the Beenakker $\mathrm{TM}_{010}$ cavity for atmospheric pressure operation of a $\mathrm{He}$ or Ar microwave-induced plasma. (1) Cylindrical wall, (2) fixed-bottom plate, (3) removable lid, (4) quartz discharge tube, (5) quartz tube holder, (6) microwave power coupling loop, (7) connector, (8) high dielectric strength insulator, (9) tuning screw, (10) tuning screw, (11) plasma viewing port, and (12) cavity support. (Reprinted from [43] with permission.)

power to the plasma; however, resonant cavities have proven to be more successful [41], [42]. The purpose of the resonant cavity is to enable the formation of a standing electromagnetic wave at microwave frequency (typically $2450 \mathrm{MHz}$ ) such that the field strength is maximized in the vicinity of the plasma torch. The resonant modes of these cavities can be classified as transverse electric (TE) or transverse magnetic (TM) modes. However, often the modes cannot be separated into purely TE or TM and are therefore called hybrid modes [41].

In 1976, Beenakker [43] designed an efficient $\mathrm{TM}_{010}$ cavity which could be used to form a plasma in either argon or helium, at atmospheric pressure, and at quite low input powers (40-100 W); this cavity has become the most popular means of forming analytical microwave plasmas. A schematic diagram of a Beenakker cavity is provided in Fig. 14 [43]. This cavity has the shape of a pillbox or pancake and consists of a cylindrical wall with a fixed bottom and removable lid. The discharge tube is mounted in the center of the cavity, perpendicular to the cylindrical walls. Microwave energy is transferred to the cavity through a coupling loop which consists of a 1-mm-thick copper wire. Cavity resonance is achieved using either a tuning stub in the bottom of the cavity or a stub through the cylindrical wall. The Beenakker $\mathrm{TM}_{010}$ cavity and variants on the principle are very stable when operated at atmospheric pressure and have gained considerable popularity in analytical spectroscopy.

\section{B. Discharge Characteristics}

Measurements of temperature and electron number density in both $\mathrm{Ar}$ and He MIP's have been summarized by Matousek et al. [42]. Both Ar and He MIP's are characterized by very high electron temperatures in the range $23000 \mathrm{~K}$ for an atmospheric pressure plasma. The high-frequency excitation used for the MIP causes electrons to be accelerated during one cycle of the applied field before a significant number of electronheavy particle or electron-electron collisions occur. As a result, the high-energy tail of the electron energy distribution is overpopulated relative to a Maxwellian distribution, and this is reflected in the measurement of high electron temperatures. 


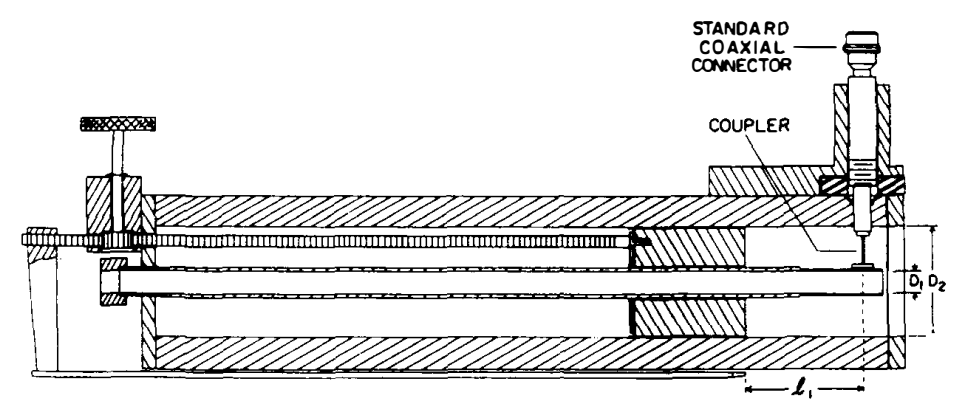

Fig. 15. Cross-sectional view of a surfatron device. The dimensions of the excitation structure $\left(l_{1}\right)$ can be adjusted using a toothed rack and pinion. Dimensions are: $D_{1}=11 \mathrm{~mm}, D_{2}=40 \mathrm{~mm}$. (Reprinted with permission from [46].)

Electron number densities are about $3 \times 10^{15} \mathrm{~cm}^{-3}$ for an Ar, and $0.5 \times 10^{15} \mathrm{~cm}^{-3}$ for $\mathrm{He}$ at atmospheric pressure. A variety of excitation temperatures has been measured for both Ar and He MIPS's, with the result being in the range of 3000--45000 $\mathrm{K}$ for both $\mathrm{Ar}$ and $\mathrm{He}$ at atmospheric pressure. Clearly, the MIP is not in LTE. While the excitation characteristics of MIP's are similar to those measured for the ICP, the volume of the plasma is much smaller (normally the dimensions of the plasma are around $1 \times 5 \mathrm{~mm}$ ), and hence the plasma is much more susceptible to mass-loading effects which limit the applications for which it can be used.

Details on the development of the MIP as an analytical source can be found in a number of excellent reviews [41], [42], [44].

\section{Surfatron}

In the 1970's a nonresonant cavity was introduced in which energy was transferred to the plasma through the propagation of an electromagnetic surface wave [45]. The surfatron plasma has found application in several areas of science and was first discussed as a spectrochemical source in 1979 [46]. A schematic diagram of the surfatron is reproduced in Fig. 15. The structure can be viewed as a length of a coaxial transmission line, terminated at one end by a short-circuit, and at the other end by a capacitive gap. Its operation is different from resonant cavities, in that the cavity is used both to impedance-match and shape the axial electric field such that its radial magnitude is greatest at the dielectric-plasma boundary. For the surfatron, the electric field is imposed by an electromagnetic surface wave propagating along the discharge tube. No external wave-guiding structure is needed, because the interface between the plasma and surrounding dielectric constitutes such a guide. The structure has a symmetry and shape which is capable of launching an azimuthally symmetric surface wave from the gap region along the length of the discharge tube. The plasma is ignited using a Tesla coil. Tuning the surfatron is accomplished by moving the plunger to the length of the cavity; no additional tuning stubs are needed. The surface wave plasma is quite stable, since only one mode of propagation is allowed. It can be operated over a broad range of frequencies $(27 \mathrm{MHz}$ to $10 \mathrm{GHz}$ ) and gas pressure (about $10^{-4}$ torr to a few times the atmospheric pressure). This provides flexibility in controlling the parameters of the plasma produced. An excellent review of the development of surface wave plasmas has recently been published [47].

\section{Applications}

One advantage of both the MIP and Surfatron, when compared with the ICP and DCP, is that they can be operated at very low powers and gas flow rates. This makes these sources attractive, because of the relatively low cost of equipment and support gas. However, these low-power plasmas are strongly affected by mass loading and the presence of molecular species introduced into them that makes it difficult to introduce solution samples directly. Therefore initial applications used the MIP for gas analysis and as a detector for gas chromatography [48], [49]. Pneumatic nebulization of aqueous solutions into a low-power MIP (100 W) can be accomplished if an aerosol desolvation system is located after the nebulization chamber to remove water vapor [50]. Alternatively, higher power can be utilized. The possibility of using a nebulizer for direct sample introduction into moderate-power MIP's $(500 \mathrm{~W})$ has been studied by Hass and Caruso [51] and Michlewicz et al. [52]. Using a modified Beenakker $\mathrm{TM}_{010}$ cavity, Hass and Caruso could maintain a stable discharge using a nebulized solution introduction rate of $1 \mathrm{ml} / \mathrm{min}$ for water. The detection limits were good; however, problems due to chemical interferences were noted. Sample introduction has also been accomplished using graphite furnace and laser-ablation sampling.

By far, the most successful application for the MIP has been as a gas chromatography (GC) detector since it provides element-specific information that simplifies the interpretation of the chromatograms of complex environmental, clinical, petrochemical, and biological samples which are sometimes difficult for more commonly used GC detectors. In the initial work, using the MIP as a GC detector, McCormack et al. [48] used a 2450-MHz atmospheric-pressure argon discharge to detect the elution of halogen and other nonmetal containing compounds from a GC. The detection limits for most nonmetal elements were found to be in the range of $10^{-12}$ to $10^{-9} \mathrm{~g} / \mathrm{s}$. The development of the Beenakker cavity stimulated renewed interest in the application of MIP's as GC detectors [53]. Recently, Hewlett-Packard has begun to market the HP 5921A MIP detector with a slew-scan photodiode array detection system for GC. This system [54] features a re-entrant cavity and a thin-walled $(0.12 \mathrm{~mm})$, water-cooled, quartz discharge 


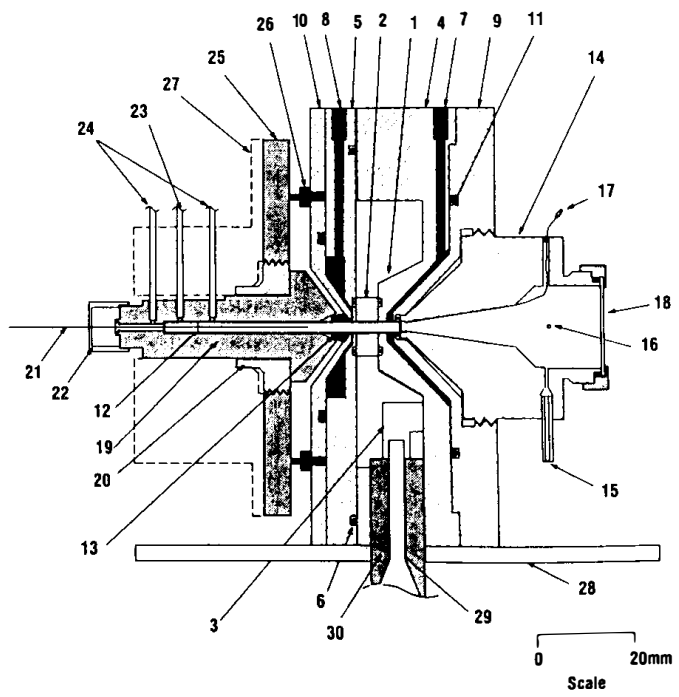

Fig. 16. Schematic diagram of the re-entrant cavity: (1) pedestal, (2) quartz jacket, (3) coupling loop, (4) main cavity body, (5) cavity cover plate, (6) gasket, $(7,8)$ cooling water inlet and outlet, $(9,10)$ water plates, $(11)$ O-ring, (12) silica discharge tube, (13) polyimide ferrule, (14) exit chamber, $(15,16)$ window purge inlet and outlet, (17) sparker wire, (18) window, (19) gas union, (20) threaded collar, (21) column from gas chromatograph, (22) column fitting, (23) auxiliary gas inlet, (24) purge flow outlets, (25) stain less-steel plate, (26) standoff, (27) heater block, (28) mounting flange, and (30) PTFE coaxial insulator. (Reprinted with permission from [54].)

tube. A schematic diagram of the cavity is provided in Fig. 16. The re-entrant cavity resembles a $\mathrm{TM}_{010}$ cavity, except that there is a pedestal in the center, the coupling loop is thicker, and the diameter is smaller. The axial pedestal provides a plasma that is shorter than the outside diameter of the cavity and also causes the electric field to be higher on the cavity axis where the quartz tube is located. Microwave power is supplied to the cavity via a waveguide which eliminates the tuner and cables and associated arcing and power-drift problems.

Plasmas operating at microwave frequencies have been investigated for several decades as sources for analytical atomic spectroscopy. Mass loading effects have not allowed them to be exploited effectively for applications involving direct introduction of aqueous aerosols; however, it has been shown that these plasmas are very efficient at exciting nonmetals (such as $\mathrm{Cl}, \mathrm{Br}, \mathrm{I}, \mathrm{P}, \mathrm{S}$, etc.), presumably the result of selective non-LTE excitation processes. These sources are nearly ideal as spectroscopic detectors for gas chromatography, since the small size is an advantage and sample introduction is in the form of volatile gases. In addition, the elements of interest for most chromatographers are nonmetals. It seems likely that the MIP will dominate this application for many years to come.

\section{Glow Discharge (GD)}

Low-pressure glow discharges (GD) have enjoyed a long history. A multitude of devices has been developed, each with special excitation and/or sampling characteristics. This type of discharge is especially interesting, since the plasma often carries out the dual role of sampling and excitation and/or ionization.

In 1916, Paschen replaced the typical planar cathode of a Geissler discharge tube with aluminum foil bent to form a hollow box-like shape open at both ends [55]. Paschen's work marked the birth of the hollow cathode discharge (HCD), an emission source which has enjoyed widespread use as a line source for atomic absorption spectroscopy since the late 1950's. This work also marked the beginning of the exploitation of glow discharges for analytical applications.

When used for the direct analysis of metals, HCD's suffer from the need for some degree of machining of the sample to form the hollow cathode. This, in part, led to the development of the Grimm glow discharge (GGD), or hollow anode discharge, in 1968 [56]. This source has achieved greater popularity than the HCD due to its use of a planar cathode (sample), thus reducing the need for any machining of the sample prior to analysis.

A current philosophy for improving analytical performance in emission methods is the separation of the process of atomization of the solid or liquid sample from that of excitation of the resulting gas-phase atoms (ions), such that each process can be independently optimized. Most emission methods, including both the HCD and GGD, provide both atomization and excitation steps so that neither step can be individually enhanced. Furnace Atomic Nonthermal Excitation Spectrometry (FANES) was developed by Falk et al. [57] in the early 1980's to provide this independent atomization and excitation. FANES uses a cylindrical furnace tube to thermally atomize the sample, and a HCD for the nonthermal excitation of the sample atoms. Analyses of samples in the picogram range were reported, comparable to some of the best detection limits from conventional practical methods.

\section{A. Discharge Characteristics}

The glow discharge is essentially a gas discharge that carries a current of between approximately $10^{-6}$ and $1 \mathrm{~A}$. The glow discharge typically requires low-pressure operation to prevent the formation of an arc, although it is possible to sustain the glow at atmospheric pressure if the cathode is adequately cooled. The glow discharge is easily identifiable by a series of alternating dark and bright spaces occurring between the electrodes, some of which are unnecessary and can be eliminated by a judicious electrode spacing. The bright spaces are either electric field-free or weak-field regions and owe their luminosity to excitation and ionization of gas-phase species. The dark spaces are regions with significantly larger electric fields acting on them, which causes acceleration of the charged particles responsible for excitation and ionization, effectively reducing collisional cross sections and therefore the luminosity of that region.

The inhomogeneous electric field is a result of the formation of space charges in the discharge. The large difference in mass between the support-gas ions and electrons, which form the bulk of the particles driven by the electric field, influences their relative mobilities in the discharge so that each congregate in different areas between the electrodes: most of the support- 
gas ions are localized around the cathode, causing almost all the discharge voltage to be dropped across the cathode dark space, a region of little light emission between the cathode and negative glow, which is a contrasting region of bright emission caused by excitation and ionization. These two regions are the only essential regions for the maintenance of the glow discharge, and are the regions used for solids sampling.

There are two types of glow discharge that can be differentiated by their voltage characteristics. The glow discharge with normal cathode fall is characterized by a constant fall of potential across the cathode dark space with increasing current flow due to incomplete coverage of the cathode. Once the glow covers the entire cathode, any increase in current flow necessitates an increase in current density, which produces an increase in discharge voltage identifying the glow discharge with abnormal cathode fall.

The increased discharge voltage provides positive ions with more energy for impact with the cathode. The energetic ion is either back-scattered from a surface atom or penetrates the solid to a few angstroms depth, where its potential energy can liberate secondary electrons and its kinetic energy can cause surface atoms to be ejected, provided that the energy transferred exceeds the binding energy of the surface atoms, a phenomenon called sputtering that can be used for solids sampling. Sample atoms can be sputtered with an appreciable velocity component away from the cathode surface, but are soon thermalized by collisions with support-gas atoms. Transport to the negative glow is therefore primarily controlled by diffusion.

The negative glow is known not to be in LTE largely due to the existence of the non-Maxwellian electron-energy distribution [58]. Electron temperatures obtained from probe measurements are characteristically up to an order of magnitude greater than spectroscopically determined excitation temperatures, which are in turn a factor of 2-5 times greater (depending on which spectroscopic emission lines are chosen) than kinetic gas temperatures elucidated from Doppler broadening. As a result, emission lines are characterized by high line-to-background intensity ratios. A pictorial representation of the sputtering, ionization, and excitation processes that occur in the glow discharge with an abnormal cathode fall is provided in Fig. 17.

\section{B. Applications}

For the HCD, both the cathode dark space and negative glow can be contained inside the hollow cathode with a judicious choice of pressure and the positioning of the anode near the open end of the cathode. The discharge ensues here rather than the outside walls of the hollow cathode due to the hollow cathode effect: at the reduced pressures typically used, mean free paths are such that electrons inside the hollow cathode can migrate from one side of the cathode to the other, where they will undergo a reversal of direction [59]. It is possible for an electron to make multiple passages through the discharge, which can greatly enhance the number of ions and photons produced. In addition, any ions and photons produced are less likely to be lost due to the closed geometry of the hollow

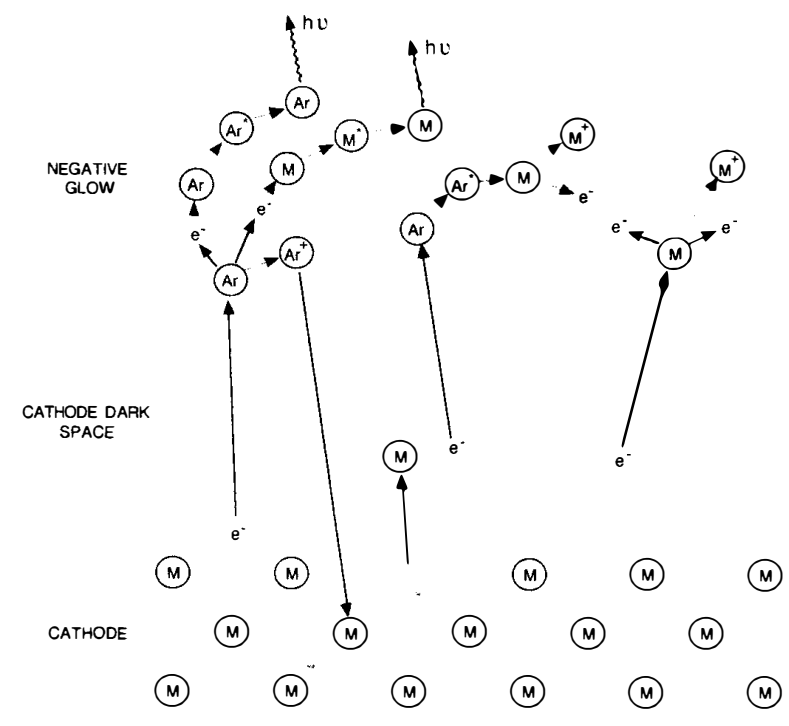

Fig. 17. Pictorial representation of interactions between the negative glow, cathode dark space, and the sample surface in a glow discharge. (Adapted from W. W. Harrison et al., Anal. Chem., vol. 58, 1986.)

cathode, and so the secondary electron production must also be greater. The current flow inside the cathode is thus far larger than that obtainable from the outside walls, and the discharge is confined inside the hollow cathode. The large number of electrons in the discharge also greatly enhances the number of excitation collisions that occur in the negative glow, which leads to a much increased light emission relative to a simple planar cathode and explains the predominance of the HCD as a line source for atomic absorption.

HCD's have also been used for quantitative atomic emission analyses. Cooled HCD's rely on cathodic sputtering for the atomization of the sample, which is usually either disc-shaped to form the bottom of the hollow cathode or machined into the hollow cathode itself. Analyses of metals, nonconducting powders, and evaporated liquids are possible with typical detection limits in the ppm range [74]. Hot HCD's, on the other hand, primarily depend on thermal evaporation for sample atomization. The sample can be incorporated into a graphite hollow cathode in the form of chips, a method that has reported detection limits below the ppm range [58]. However, HCD's have not achieved a great popularity for routine quantitative analyses due to the cathode preparation required.

The GGD or Grimm lamp, shown schematically in Fig. 18, only requires a sample with a flat surface to form a vacuum seal between the inside of the vacuum vessel and the outside atmosphere. This aspect is additionally attractive, in that it increases the possible turn-around-time between samples. But perhaps the most important ability made possible by the flat surface of the cathode is controllable depth profiling. In the hollow cathode there are areas that undergo heavy sputtering, such as the cathode bottom and mouth, but also areas of comparatively light sputtering inside the hollow. In contrast, GGD sputtering is an easily controllable layer-by-layer re- 


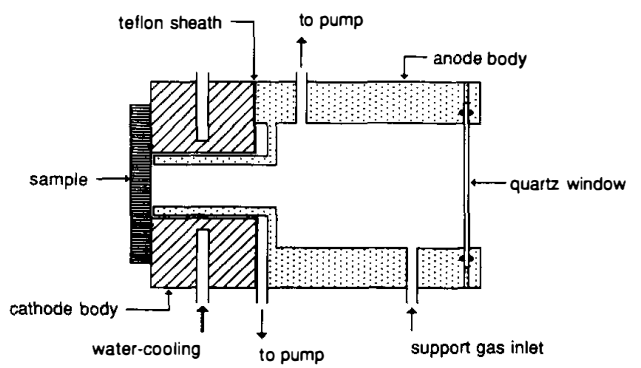

Fig. 18. Cross-sectional view of a GGD source. The sample is normally machined flat, such that it will form a seal with the cathode body. The sample is sputtered by support gas ions and diffuses to the negative glow region from which emission is observed.

moval of cathode atoms. Penetration rates can be determined by weight-loss measurements [60] and correlated with the temporal response of the emission signals to give elemental concentrations with depth. However, this controllable, uniform sputtering is largely at the expense of the enhanced sputtering and emission prevalent in the hollow cathode.

In the GGD the distance between a hollow cylindrical anode and a planar cathode is less than one mean-free path of the electrons in the discharge [58]. This prevents the discharge from forming anywhere but at the cathode surface bounded by the internal diameter of the anode. This obstructed discharge quickly in itiates an abnormal cathode fall, but electrons cannot undergo multiple passages through the negative glow. As a result, there are relatively fewer excitation or ionization collisions in the GGD compared with the HCD. This is reflected in the detection limits for GGD's, which are approximately an order of magnitude higher than those typical with an HCD [58].

There have been many efforts to improve both the sputtering and excitation ability in the HCD and GGD. Both sources [61], [62] have had magnets incorporated into their designs in an attempt to increase both these parameters. The applied magnetic field forces the free electrons in the discharge to follow a helical motion about the electrical lines of force that increases their displacement through the negative glow, making an exciting or ionizing collision more probable. Although the magnet does indeed increase both parameters, it renders the source sensitive to the magnetic properties of the sample and can produce split calibration curves.

Sacks' research group has investigated the use of magnetically enhanced glow discharges using a device called a planar magnetron [63]. For this device, a magnet is placed behind the cathode and the ensuing magnetic field acts to trap plasma electrons in circular orbits parallel to the cathode (sample) surface. This greatly increases the effective pathlength for electrons in the plasma, which in turn enhances their ionization efficiency. This results in a reduction in the plasma sheath and, as a result, sputtering can be carried out at pressures as low as $10^{-5}$ torr.

Auxiliary excitation of the negative glow by secondary dc, $\mathrm{RF}$, and microwave discharges has also been attempted in both the HCD [61] and GGD [64]. Although enhanced excitation

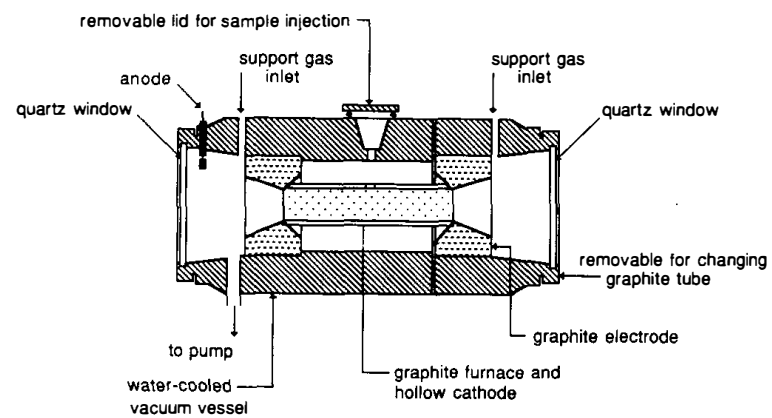

Fig. 19. Cross-sectional view of a FANES source. A small volume of liquid sample is pipetted onto the graphite furnace wall and dried by passing a low current through the furnace. The pressure is reduced, a glow discharge struck, and the analyte is vaporized off the furnace walls by application of a high current. Emission is viewed axially. (Adapted from H. Falk et al. Spectrochim. Acta, vol. 39B, 1984.)

of sputtered atoms is evident, the auxiliary discharge interferes with the sputtering ability of the primary discharge. A more consummate separation of atomization from excitation should provide even greater performance, and as a consequence lower detection limits.

This consummation has been achieved to a large degree by the FANES source shown schematically in Fig. 19. In this method, a graphite furnace similar to that commonly used in atomic absorption is used partly in the conventional manner to thermally atomize samples, but also as a hollow cathode to form an HCD at reduced pressures in which any thermally released atoms can be excited. Any sputtering initiated by the HCD is negligible compared to the thermal release of cathode material [65]. The thermal release increases the amount of sample to reach the negative glow relative to sputtering due to redeposition problems inherent with the sputtering process. Up to $90 \%$ of sputtered atoms redeposit on the cathode during conventional sputtering [60], but if the cathode temperature is higher than the boiling point of the sample, any redeposition can be severely retarded. This is apparent by the low-detection limits demonstrated by FANES that are comparable to graphite-furnace atomic absorption spectrometry (GFAAS) but, similar to other emission methods, also has the ability for simultaneous multielement analyses and a dynamic range of five to six orders of magnitude [65]. In 1990, C. Zeiss/JENA introduced a commercial FANES system, the Fanoquant 100; however, it was withdrawn from the marketplace shortly thereafter.

A variation on the FANES source has recently been developed by Ballou et al., in which a graphite furnace forms the anode (rather than a cathode as for FANES) and a graphite rod located along the central ax is of the furnace serves as the counter electrode [66]. Although this hollow anode FANES (HA-FANES) can no longer benefit from the hollow cathode effect, the small surface area of the cathode permits more stable operation and the attainment of large current densities, allowing a relatively high-pressure operation compared to other glow discharge devices. It has been demonstrated that for this device, an increase in pressure produced an increase in 
signal due to longer analyte residence times in the furnace [67]. The HA-FANES source has been used to carry-out analyses at a pressure of 600 torr [68], and it is believed that atmospheric operation, while retaining analytical performance, is possible, greatly simplifying repetitive sample introduction.

Thermal atomization, used in both the FANES and HAFANES methods, is not free from problems, however. Certain elements are more readily released than others at the temperatures typically used in furnaces. For example, $\mathrm{Al}$ and $\mathrm{W}$ at $2000^{\circ} \mathrm{C}$ have evaporation rates which differ by approximately nine orders of magnitude. Conversely, sputtering yields in a conventional glow discharge differ by less than a factor of two for these two elements [69]. In general, sputtering yields for other elements rarely vary by more than a factor of ten. Even this relatively small variation may be diminished provided that sampling is prolonged, since surface enrichment of poorly sputtered species tends to normalize sputtering yields. Although sputtering affords more uniform atomization, it still suffers from the redeposition problem previously outlined; therefore any mechanism that retards this process would make sputtering more advantageous.

This problem has been addressed by the Atomsource ${ }^{\mathrm{TM}}$, manufactured by the Analyte Corporation [70]. This source uses a Grimm-type design, but the tubular anode contains six hexagonally arranged jets to direct a symmetrical flow of support gas from the side onto the surface of the sample, which produces a resultant flow of gas away from the center of the sample. The redeposition process is somewhat slowed as evidenced by a sample loss rate approximately three times that of a conventional Grimm design [71], but this does not account for all of the estimated $90 \%$ redeposition. In addition, craters form on the sample where the jets impinge, thus precluding any depth profiling. It appears that further research into this problem is required.

Since the material volatilized is essentially ground-state atoms, glow discharges are suitable atomizers for detection by atomic absorption and fluorescence. Gatehouse and Walsh were the first to use sputter atomization for atomic absorption spectrometry [72]. Contributions from a fellow CSIRO member some years later demonstrated that the use of an internal standard improved the already impressive inherent precision of glow discharge analyses [73]. A particularly interesting glow discharge apparatus was the nondispersive resonance fluorescence spectrometer developed by Human et al. [74]. This spectrometer incorporated a GGD as primary source, containing the sample to be analyzed as its cathode. A second glow discharge was used as a source that contained a pure hollow cathode composed of the sought-after element. Since fluorescence detected is directly proportional to the intensity of the incident radiation from the primary source, quantitative analyses of the Grimm cathode were possible. This design was subsequently improved by Bubert to allow the fast sequential analysis of up to six elements by housing different hollow cathodes on a carousel assembly [75].

A method using glow discharges that is gaining in prominence and has a bright future is glow-discharge mass spectrometry (GDMS). The negative glow contains a significant population of energetic electrons and support-gas atoms in metastable states, which can ionize sufficient numbers of sputtered atoms to allow its use as an ion source for mass spectrometry. Mass spectrometric detection provides sufficiently fast sequential detection to be comparable to simultaneous multielement analysis, but is also characterized by lower detection limits and simpler spectra relative to emission methods and also allows the procurement of isotopic information.

Harrison et al. were the first to interface a glow discharge to a quadrupole mass filter [76]. Although the analytical performance was promising, they found a preponderance of interfering atomic and molecular ions that could not be separated by the low-resolution mass analyzer. Later studies improved upon this performance, but did not eliminate the problems [77]. For this reason the first commercial glow discharge mass spectrometer, offered by VG Isotopes, incorporated a highresolution double sector instrument. However, this resolving power is achieved at a significantly greater cost, making it inaccessible to most research laboratories. Research is ongoing, however, to provide a cost-competitive glow-discharge mass spectrometer.

Although a typical dc glow discharge is confined to analyzing either conducting samples or nonconducting samples mixed in a conducting matrix, an RF discharge has the ability to analyze nonconducting samples without preparation. In addition, the RF discharge operates at pressures of about a tenth of that normally used in its dc cousin, which should reduce the production of any molecular species in the negative glow and enhance depth-profiling resolution relative to its dc cousin [78]. The RF discharge has been used extensively for thinfilm-deposition applications, especially in the microelectronics industry, but is now gaining acceptance among analytical chemists as a sampling tool, and several laboratories are now investigating the performance advantages possible with this device.

Although conceptually the glow discharge is a "dated" source in terms of chronological history, it is by no means obsolete technology - new designs, modifications, applications, and fundamental studies concerning the processes that govern glow-discharge operation have been appearing in the scientific literature at an ever-increasing rate during the last ten years. For example, recently, two issues of Spectrochimica Acta $B$ were devoted entirely to analytical applications of glow discharges [79]. The simple cost-effective instrumentation that performs direct solids sampling with superior analytical performance for many applications is in large part responsible for this growth.

\section{Vi. Capacitively Coupled RF Plasmas, Capacitive Microwave Plasmas, and RF Flowing AFterglow Plasmas}

\section{A. Capacitively Coupled Plasmas}

The principle of capacitive coupling to generate a plasma has been known for many years. In 1941, Cristescu and Grigorovici [80] reported that a capacitively coupled plasma (CCP) discharge could be produced between two circular plates, separated by up to $15 \mathrm{~cm}$. The plates formed a capacitor 
that, as part of the resonance circuit, determined the frequency of the RF generator, typically in the range of 60 to $90 \mathrm{MHz}$. The lower plate had a copper cone with a platinum tip at which a high field strength was produced. By touching the tip with an electrically isolated conductor to generate seed electrons, a discharge was formed at the tip; it was reported to have had a temperature of $4000 \mathrm{~K}$ at an RF power of $650 \mathrm{~W}$.

Egorova [81] used a CCP with two external annular electrodes at each end of a water-cooled discharge tube for spectrochemical analysis of nebulized solutions. The plasma was run at atmospheric pressure in argon and was viewed along its axis. Zvyagintsev et al. [82], [83] developed an electrodeless capacitive arc (plasmatron) in air at atmospheric pressure. The discharge torch consisted of two external annular electrodes similar to the device described by Egorova. The plasma was operated at $150 \mathrm{MHz}$ and a few kilowatts of power, with an air flowrate of 30-600 L/min. The temperature reported for the plasmatron was $5500 \mathrm{~K}$.

This double-electrode annular geometry, although on a much smaller scale, was recently offered commercially as a gas chromatography detector by Anton-Parr (Austria) [84]. The torch consists of a $0.5-\mathrm{cm}$ diam, water-cooled discharge tube made of fused silica. The output of a 27.12-MHz RF generator is impedance-matched to two annular electrodes separated by a short distance. The capacitive discharge utilizes $\mathrm{He}$ as the plasma gas and normally operates at an RF power of $150 \mathrm{~W}$.

In 1984, Elliot [85] described an RF capacitively coupled plasma jet device intended for spectrochemical analysis in a manner similar to the use of the DCP. The torch consisted of two RF plasma jets arranged in an inverted- $V$, such that the plasma jets met at a common point and the nebulized solution was directed at the intersection. The main difference between the Elliot CCP jet and those of Egorova and Zvyagintsev was that one of the annular electrodes was smaller and was placed inside the discharge tube rather than around the outside.

RF parallel-plate capacitively coupled discharges have been widely used for plasma etching of semiconductors at low pressure. The possibility of using a parallel-plate, $13.56-\mathrm{MHz}$, $\mathrm{RF}$, capacitively coupled, low-pressure oxygen plasma for spectrochemical analysis was investigated by Winslow in 1980 [86]. The quartz plasma chamber was cylindrical in shape, with a length of $16 \mathrm{~cm}$ and radius of $4 \mathrm{~cm}$. Two RF electrodes consisting of a condenser were located outside the plasma chamber. They were isolated from the plasma gas so that no electrode contamination existed. Capacitive coupling was the only mechanism of energy transfer.

An elongated atmospheric-pressure RF CCP discharge has been developed by Liang and Blades [87] for atomic absorption and emission analysis of small, discrete sample volumes (1-10 $\mu \mathrm{L})$. A schematic diagram of the device is provided in Fig. 20. Functionally, the device consists of two parts, the CCP discharge, which is a cylindrical or square-bore quartz tube with opposing parallel-plate electrodes, and a tantalumstrip, electrothermal vaporization, sample introduction system. This CCP device has been demonstrated as being potentially useful not only for both atomic absorption spectrometry and atomic emission spectrometry, but also as a detector for gas chromatography (GC) [88], [89].

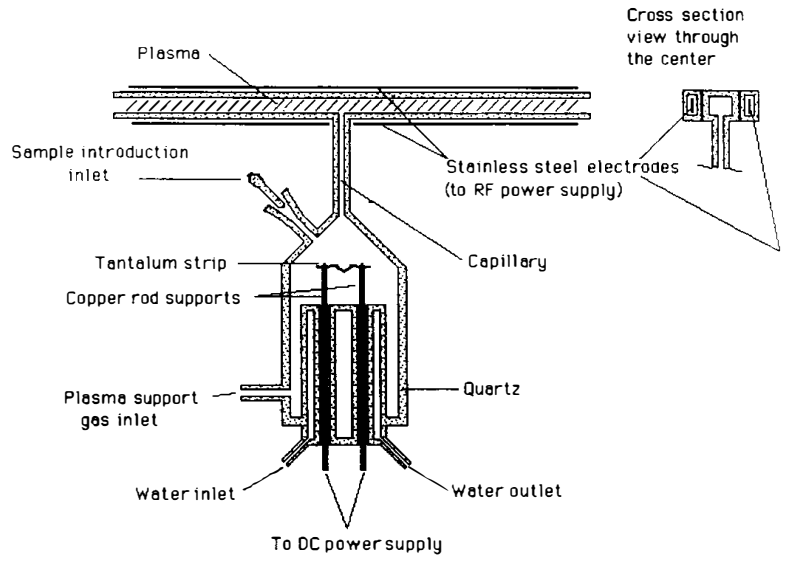

Fig. 20. Cross-sectional view of the T-shaped CCP torch developed by Liang and Blades [87]. RF power is coupled into the plasma by using two parallel opposing plates placed outside the quartz discharge tube (see inset). Small volumes of a liquid sample are placed on the tantalum strip and are electrothermally vaporized into the plasma discharge. Absorption or emission analysis can be carried out on the plasma.

FAPES (furnace atomization plasma excitation spectrometry) is the acronym that has been used to describe a relatively new CCP source for analytical atomic spectroscopy. The construction and operation of this source was first described by Liang and Blades [90]. The FAPES source enables the formation of $\mathrm{He}$ or Ar plasmas at atmospheric pressure inside an otherwise normal graphite-furnace atomizer. The plasma is formed and sustained at atmospheric pressure by placing high-voltage RF excitation on a conductive electrode located inside the graphite furnace with a co-axial geometry, while maintaining the furnace at virtual ground. A schematic diagram of the FAPES-CCP is provided in Fig. 21. The radius of the graphite tube is $0.25 \mathrm{~cm}$ and the length is $1.5 \mathrm{~cm}$. A gas flow through the furnace is not required, although a flow of about $20-30 \mathrm{~mL} / \mathrm{min}$ around the graphite furnace is used. Excitation temperatures for the FAPES source have been reported to be in the range of 2900 to $5000 \mathrm{~K}$ [91], [92]; however, the results are preliminary and full parametric studies have not yet been undertaken. During routine operation for analytical determinations, a sample (normally $5-50 \mu \mathrm{L}$ ) is deposited inside the graphite furnace through a dosing hole located in the top of the graphite tube, and the sample is atomized into the plasma by electrically heating the graphite tube. Atoms in the vaporized sample are excited by the plasma and emit at their characteristic wavelengths, such that the FAPES source can be used for simultaneous multielement analysis. Since the initial descriptions of the FAPES source [90], [93], some analytical [94], [95] and fundamental [91], [92] characteristics have been reported. Even at this very early stage of development, FAPES promises to provide a method of carrying out simultaneous multielement analysis on small liquid and solid samples with detection limits that are the same order of magnitude as those provided by graphite-furnace atomic-absorption spectrometry.

An unusual CCP has been formed by placing a water-cooled 


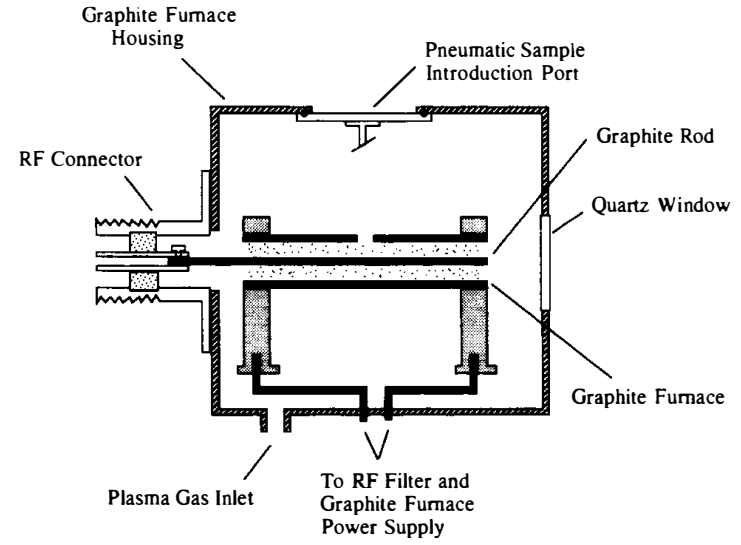

Fig. 21. Schematic diagram of the atmospheric-pressure CCP formed inside a graphite tube [90]. Small volumes of a liquid sample are placed inside the graphite through a sampling hole and are electrothermally vaporized into the plasma discharge contained inside the tube. Emission is observed axially.

grounded electrode above a helium inductively coupled plasma (ICP) [96]. In comparison to the results of a helium ICP, the plasma stability was enhanced and the power required was reduced significantly. The detection limits of nonmetals obtained with this plasma at $500 \mathrm{~W}$ were either comparable or superior to those with the helium ICP at $1500 \mathrm{~W}$. The electron number density for this discharge is greater than that for the helium ICP.

\section{B. Flowing Afterflow Plasmas}

In 1980, D'Silva et al. [97] used an atmospheric-pressure active nitrogen (APAN) discharge for analytical spectroscopy. The APAN torch consisted of two coaxial, concentric-fused silica tubes of 1.8 and $2.6 \mathrm{~cm}$ diam and approximately 40 $\mathrm{cm}$ in length. Copper-foil electrodes were positioned inside the inner tube and around the outside of the outer tube. The geometry and power coupling of this APAN torch were very similar to designs used for ozonizers. An annular afterglow discharge could be formed in the gap between the two quartz tubes at $1800-\mathrm{Hz}$ frequency, $500-\mathrm{W}$ power, and $20-\mathrm{kV}$ ac potential [97]. The APAN is essentially a low-frequency capacitive discharge in nitrogen. This device was used for the determination of $\mathrm{Hg}$ - and hydride-forming elements ( $\mathrm{As}, \mathrm{Bi}$, $\mathrm{Ge}, \mathrm{Pb}, \mathrm{Sb}, \mathrm{Se}, \mathrm{Sn}$, and $\mathrm{Te}$ ) and exhibited detection limits between 0.02 and $50 \mathrm{ng}$, depending on the element.

More recently, the preferred implementation of flowing afterglow plasmas has utilized $\mathrm{He}$ as the plasma gas and the geometry depicted in Fig. 22 [98]-[100]. The He-discharge afterglow plasma is normally operated at frequencies between 25 and $300 \mathrm{kHz}$, at a power of $50 \mathrm{~W}$ and plasma gas-flow rate of $80 \mathrm{~mL} / \mathrm{min}$. The proposed use is as an element-selective detector for gas chromatography. Detection limits for this device are certainly competitive with the MIP in the range of 0.5 to $100 \mathrm{pg} / \mathrm{s}$, depending on the element.

\section{Capacitive Microwave Plasmas}

Microwave plasmas can be classified into two groups:

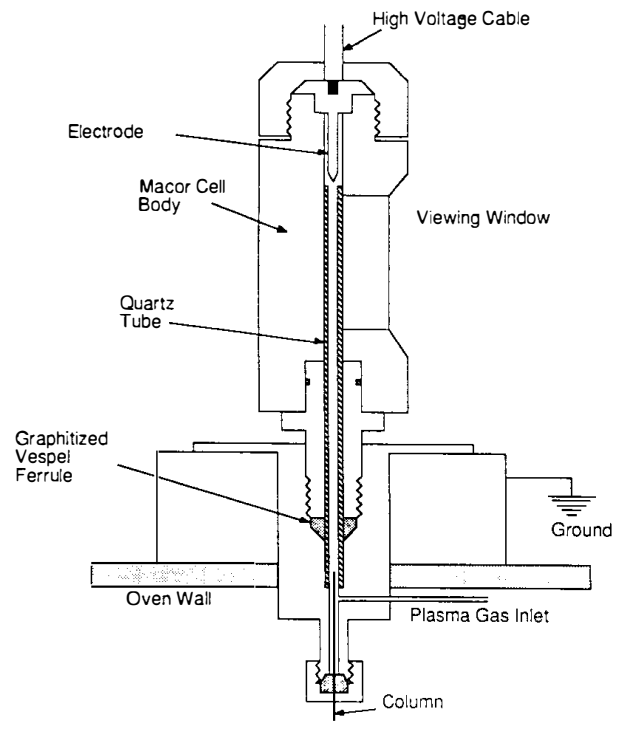

Fig. 22. Schematic diagram of the He-flowing afterglow torch used as a chromatographic detector. An He plasma is formed inside the quartz tube. Effluent from the gas chromatograph is introduced into the plasma through the column inlet at the base of the torch. (Reprinted with permission from [99].)

microwave-induced plasmas (MIP), which have been discussed previously, and capacitively coupled microwave plasmas (CMP). In the first type, the microwave energy is coupled to the plasma in a discharge tube within a resonant cavity. In the second type, microwaves, generated using a magnetron, are delivered to a single-electrode torch through a rectangular waveguide. The latter type of microwave plasma torch has not been utilized as extensively as the former, apparently because of electrode erosion and contamination. These devices have the advantage of being able to tolerate the introduction of water vapors, are extremely stable at low and high powers, and can be operated using a variety of support gases, including $\mathrm{Ar}$, $\mathrm{He}, \mathrm{N}_{2}$, and air.

Most CMP sources are derived from the designs of Cobine and Wilbur [101] and Schmidt [102] and operate in the frequency range of $500-2450 \mathrm{MHz}$. Winefordner et al. [103]-[105] have developed several new torch designs for the CMP employing Ta and W tubular electrodes through which the sample is introduced.

Excitation temperatures for these tubular CMP torches were found to be in the range of $6000 \mathrm{~K}$ for $\mathrm{He}, 5000 \mathrm{~K}$ for $\mathrm{N}_{2}$, and $5400 \mathrm{~K}$ for $\mathrm{Ar}$ [103]. Huang et al. [106] have carried out Thompson-scattering measurements on a $350-\mathrm{W}$ CMP torch and found that both $\mathrm{Ar}$ and $\mathrm{He}$ plasmas deviate substantially from LTE. The measured electron temperatures were in the range of 13000 to $21500 \mathrm{~K}$, whereas the gas temperatures were lower by a factor of two to ten. The electron temperature of the He plasma was found to be $3500-7000 \mathrm{~K}$ higher than that measured for an Ar plasma. Electron number densities were found to be between $1 \times 10^{14} \mathrm{~cm}^{-3}$ for $\mathrm{He}$ plasma and $1 \times 10^{15} \mathrm{~cm}^{-3}$ for Ar plasma. Not surprisingly, the electronenergy distribution was found to be non-Maxwellian. 


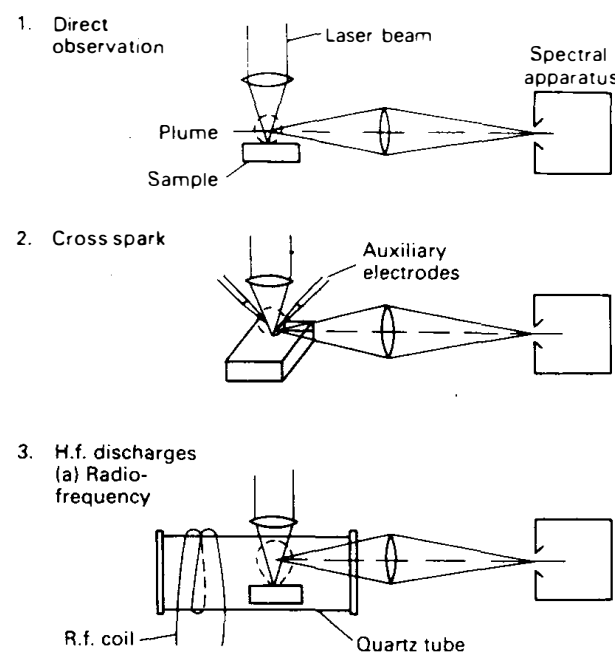

(b) Microwave
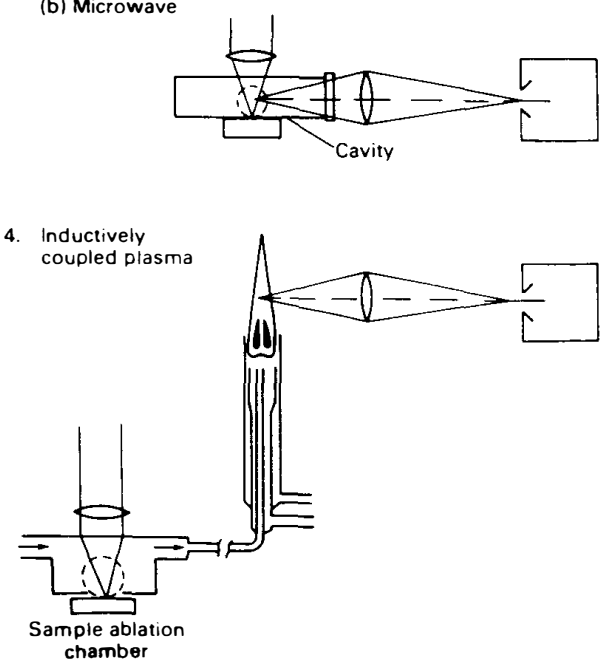

Fig. 23. Summary of methods utilizing laser ablation in analytical atomic spectrometry. (1) Direct observation of emission from the plasma plume. (2) Use of a spark discharge to excite species produced from laser ablation. (3) Ablation inside RF and microwave discharges. (4) Transport of the ablated material to an ICP for subsequent emission or mass spectrometric (not shown) analysis. (Reprinted with permission from G. Tolg, Analyst, vol. 112, 1987.)

\section{Applications}

Applications of the CCP, CMP, and flowing afterglows can be found in almost all areas of analytical atomic spectroscopy, although very few of these devices are available commercially. The most usual application of CMP and CCP torches has been in analytical applications similar to those for which ICP-OES has been used. Early results for an argon CCP reported by Egorova [81] for 24 elements were in the range of $0.5-30$ and $0.05-0.3 \mathrm{ppm}$ using a pneumatic nebulizer and an ultrasonic nebulizer, respectively. In 1975, Boumans et al. [107] compared the analytical performance of a CMP to an ICP for simultaneous multielement emission spectrometry.
They found that the ICP was superior both in terms of detection limits and freedom from chemical interferences. Nevertheless, some researchers have continued to develop applications for the CMP. The most promising application for CCP, CMP's, and He-afterglow plasmas is as detectors for gas chromatography [84], [85], [88], [89], [98], [99].

The coaxial CCP or FAPES source [90]-[95] is a potentially very exciting new spectrochemical plasma. This source combines the high efficiency of atomization in graphite furnaces with the high efficiency of the excitation in atmospheric pressure plasmas. The most important aspect of this new source is that it can be used for simultaneous multielement determinations of small sample sizes in an atomizer (the graphite furnace) which has been proven to be effective over many years of use.

There is great diversity in the kinds of RF CCP which have been used for analytical spectroscopy. This mode of power coupling allows for flexibility of choice for power, frequency, gas-flow rate, and the size and shape of the plasma torch. Even though the commercial impact has been minimal, many researchers continue to develop new devices and investigate novel sample-introduction strategies and expanded areas of application.

\section{LASER-Produced Plasmas (LPP)}

Since the discovery of laser action in ruby crystals [108] there has been extensive use of lasers in science. The first use of laser-produced plasmas (LPP) in chemical analysis appeared in 1962, when Brech et al. [109] proposed laser microspectral analysis (LMSA) as a useful analytical tool, based upon atom ic emission spectroscopy (AES), of the plume created by an LPP. The main advantage of using a laser-produced plasma as a source/sampling method is that of speed and simplicity. Laser-produced plasmas sample the surface of a solid directly, allowing spot analysis with minute sample destruction $(50-\mu \mathrm{m}$ crater) of both conducting and dielectric materials.

Laser-produced plasmas used as sources and in materials sampling have undergone several evolutionary stages. Emission studies dominated the development of LPP as sources, but were quickly followed by techniques based on absorption and fluorescence. It is only recently that LPP have been used as a sampling technique for other analytical methods such as inductively and capacitively coupled plasmas and mass spectrometry.

There are many excellent reviews on the plasmas generated by the interaction of laser light with solids: Radziemski and Cremers [110], Moenke-Blankenburg [111], Adrain and Watson [112], Fürstenau [113], [114], Hughes [115], Krokh in [116], deMichelis [117], and Ready [118]-[120]. The most recent articles emphasize analytical applications of LPP, while the earlier reviews concern high-density plasmas of interest in laser-induced fusion research.

\section{A. Plasma Generation and Characteristics}

The interaction of a high-power laser pulse impinging upon a solid target is a complex process dependent upon the thermal properties of the target as well as the wavelength, duration, 
and irradiance of the laser pulse. Initially, intense localized heat ing causes a rapid surface temperature increase of about $10^{10} \mathrm{Ks}^{-1}$. This heat is then conducted to the target interior producing a thin molten layer below the surface. Eventually, the energy absorbed by the target exceeds the latent heat of vaporization, resulting in the evaporation of material from the target surface. At this stage, evaporation processes govern surface temperature and heat conduction acts only to preserve the thin molten layer behind the evaporation front.

Since target vaporization relies upon the energy absorbed by the molten layer exceeding the latent heat of vaporization $(L v)$, Krokhin [116] gives the threshold condition:

$$
E_{\mathrm{min}}=r L_{v} a^{1 / 2} t_{l}^{-1 / 2}
$$

where $E_{\min }$ is the minimum absorbed irradiance for evaporation, $r$ is the mass density of the target, $a$ is the thermal diffusivity, and $t_{l}$ the laser-pulse duration. Below the threshold $E_{\text {min }}$ no sample evaporation will occur. The mode of operation of the laser is an important consideration, since $t_{l}$ can vary greatly. A normal-mode laser pulse consists of a series of output pulses over 150-300 $\mu$ s, whereas a Q-switched (QS)mode laser pulse is a single higher intensity pulse typically less than $100 \mathrm{~ns}$.

After the sample has been vaporized, plasma production must be considered. For irradiances just above the vaporization threshold (10 to $100 \mathrm{GWm}^{-2}$ ), evaporation proceeds at the boiling temperature of the target, giving a low-density plasma that is transparent to the laser beam. The expansion velocity and temperature of this plasma depend on the thermal properties of the target and not the laser irradiance. These low density and temperature plasmas are of use in atomic absorption spectroscopy (AAS), but their low temperatures may give increased matrix effects, making them undesirable as analytical sources.

Alternatively, irradiances well over the threshold (> $1 \mathrm{PWm}^{-2}$ ) generate extremely dense high-temperature plasmas such as those used in laser-induced fusion studies. Plasmas produced by irradiances between these extremes $\left(100 \mathrm{GWm}^{-2}-1 \mathrm{PWm}^{-2}\right)$ are generally the LPP used in LMSA and other methods. The vapor pressure of these plasm as can be so high that laser absorption is an important process, assumed to occur in a thin, dense, partially ionized layer between the solid and vapor phases. As the electron density $\left(n_{e}\right)$ of this layer approaches the critical electron density $\left(n_{c}\right)$, the target becomes shielded from laser light. Furthermore, light is reflected by the plasma if the wavelength is greater than the plasma wavelength $\lambda_{p}[114]$

$$
\lambda_{p} \approx 10^{-15}\left(n_{e}\right)
$$

where $n_{e}$ is in $\mathrm{m}^{-3}$, and $\lambda_{p}$ is in nanometers. Blackbody radiation of the hot gas is the dominant radiative process until the plasma volume increases, such that $n_{e}$ is less than $n_{c}$. After the electron density has fallen below $n_{c}$, the vapor becomes highly absorbing and enters a "self-regulating" regime. Laser light is absorbed by an inverse bremsstrahlung effect, causing heating and expansion that further reduce the vapor density. This allows more light to reach the target and repeats the process, with the critical density boundary approaching the laser at velocities as high as $10 \mathrm{kms}^{-1}$. This process continues until the laser pulse is removed, after which decay and cooling of the plasma ensues.

The high expansion velocity and irradiance of the plasma produces a significant ablation pressure which can affect the laser-target interaction. For a laser operating in the normal mode, the continuous heating/cooling of the target results in a pool of molten material behind the evaporation front. This molten pool is subsequently ejected by the high ablation pressure to form craters $50-100-\mu \mathrm{m}$ deep. In the QS mode, shorter-lived plasmas are generated with significantly higher ablation pressures. Evaporation of the target occurs at a much higher temperature than the normal boiling point, with most material removed to the vapor phase. The craters formed in the QS mode are typically much shallower (few micrometers) than those produced by a laser operating in the normal mode.

\section{B. Applications}

The use of LPP's as sources and in material sampling has many advantages. Because small amounts of practically any solid sample can be readily analyzed with minimal preparation, errors associated with sample preparation are minimized. The emission of LPP can be studied directly for a sample, but often enhancements in plasma emission are achieved by using additional excitation such as spark, microwave, or RF discharges applied to the plasma. Some methods that have been applied are outlined in Fig. 23. Similarly, absorbance, and fluorescence-based techniques can also be applied to LPP, but they must be specialized to deal with the relatively short-lived and dynamic nature of the plasma.

Laser-produced plasmas can also be used as a sampling method for the ICP, MIP, and CCP. An ablation cell is employed for this purpose in which the ablated sample is entrained in a stream of inert gas and then swept into the source as a particulate aerosol. This method of sampling has been gaining popularity recently and several manufacturers have introduced laser-ablation sampling systems for use with ICP-MS. A review of the application of laser sampling coupled with ICP-MS detection was recently published [121].

A similar arrangement is used in direct laser-ablation mass analysis, except that the bulk of the inert gas is removed from the analyte gas stream with a skimmer device prior to introduction into the mass spectrometer. Recent research reflects an increased interest in the coupling of lasers and mass spectrometry [122], and much progress can be anticipated in the near future.

The use of LPP's as analytical sources and in materials sampling has enormous potential. Their use in laser microspectral analysis will remain as a useful technique in the future, because of the speed and simplicity and the minimal sample preparation required in many cases. This technique al lows spot sampling of both conducting and dielectric materials with minimal destruction, making it very versatile. 
TABLE III

Summary of the Characteristics of Some Common Plasma Sources usedfor ANalytical Spectroscopy (InCluded are the Source, Method of Application Approximate Detection limit, Applicability for Solid Sampling,

Susceptability to Matrix Effects, Approximate Cost (IN \$1000), and the Most Common Usage for the Method)

\begin{tabular}{|c|c|c|c|c|c|c|c|}
\hline Source & Method & $\begin{array}{l}\text { Detection } \\
\text { Limit }\end{array}$ & Solid Sampling & $\begin{array}{l}\text { Matrix } \\
\text { Effects }\end{array}$ & $\begin{array}{l}\text { Cost } \\
\$ 1000\end{array}$ & $\begin{array}{c}\text { Frequency of } \\
\text { Use }\end{array}$ & Common Usage \\
\hline \multirow[t]{3}{*}{ ICP } & ICP-AES & $\begin{array}{l}0.1-10 \\
\mathrm{ng} / \mathrm{mL}\end{array}$ & with laser & low & $70-200$ & ++++ & \multirow{3}{*}{$\begin{array}{l}\text { multielement solution analysis of environ- } \\
\text { mental, geomechemical, petroleum, agri- } \\
\text { cultural samples }\end{array}$} \\
\hline & ICP-MS & $\begin{array}{l}0.001-1 \\
\mathrm{ng} / \mathrm{mL}\end{array}$ & with laser & low & $300-400$ & ++ & \\
\hline & ICP-AFS & $\begin{array}{l}0.1-10 \\
\mathrm{ng} / \mathrm{mL}\end{array}$ & with laser & low & $50-100$ & + & \\
\hline DCP & DCP-AES & $\begin{array}{c}1-50 \\
\mathrm{ng} / \mathrm{mL}\end{array}$ & -+- & moderate & $50-100$ & ++++ & $\begin{array}{l}\text { multielement solution analysis particularly } \\
\text { with high dissolved }\end{array}$ \\
\hline \multirow[t]{3}{*}{ MIP } & \multicolumn{7}{|l|}{ MIP-AES } \\
\hline & $\begin{array}{l}\text {-pneumatic } \\
\text { neb. }\end{array}$ & $\begin{array}{l}10-100 \\
\mathrm{ng} / \mathrm{mL}\end{array}$ & --- & moderate-high & $\begin{array}{l}\text { not com- } \\
\text { mercial }\end{array}$ & 0 & research and academic labs \\
\hline & $\begin{array}{l}\text {-gc detec- } \\
\text { tor }\end{array}$ & $1-50 \mathrm{pg} / \mathrm{s}$ & --- & & $30-50$ & + & gc detection of complex organic mixtures \\
\hline \multirow[t]{3}{*}{ GD } & GGD-AES & $500-5000$ & yes & moderate & $10 \bullet-150$ & + & \multirow[b]{2}{*}{$\begin{array}{l}\text { analysis of metals and depth profiling of } \\
\text { laminated materials as with GGD-AES }\end{array}$} \\
\hline & GGD-MS & $5-20 \mathrm{ng} / \mathrm{g}$ & yes & moderate & $200-600$ & + & \\
\hline & FANES & $\begin{array}{l}0.01-1 \\
\mathrm{ng} / \mathrm{mL}\end{array}$ & no & moderate & $\begin{array}{l}\text { not com- } \\
\text { mercial }\end{array}$ & 0 & research and academic labs \\
\hline $\mathrm{CCP}$ & $\begin{array}{l}\text { AES-gc } \\
\text { detection }\end{array}$ & $1-50 \mathrm{pg} / \mathrm{s}$ & --- & --- & $\sim 50$ & 0 & research and academic labs \\
\hline $\mathrm{CCP}$ & FAPES & $\begin{array}{l}0.01-1 \\
\mathrm{ng} / \mathrm{mL}\end{array}$ & no & ???? & 30 & 0 & research and academic labs \\
\hline CMP & CMP-AES & $\begin{array}{l}\sim 1000 \\
\mathrm{ng} / \mathrm{mL}\end{array}$ & no & moderate-high & $\begin{array}{l}\text { not com- } \\
\text { mercial }\end{array}$ & 0 & research and academic labs \\
\hline $\begin{array}{c}\text { RF- } \\
\text { Afterglow }\end{array}$ & $\begin{array}{l}\text { gc } \\
\text { detection }\end{array}$ & $1-50 \mathrm{pg} / \mathrm{s}$ & -- & --- & $\begin{array}{l}\text { not com- } \\
\text { mercial }\end{array}$ & 0 & research and academic labs \\
\hline Spark & Spark-AES & $\begin{array}{c}\sim 1000 \\
\mathrm{ng} / \mathrm{g}\end{array}$ & yes & low-moderate & $\$ 100-150$ & ++++ & $\begin{array}{l}\text { metal analysis in foundries and sampling } \\
\text { conducting solids }\end{array}$ \\
\hline LLP & & & & & & 0 & $\begin{array}{l}\text { used primarily as a sampling method for } \\
\text { ICP-MS }\end{array}$ \\
\hline
\end{tabular}

Frequency of use: +++++- common in many analytical laboratories ( $>6000$ units); ++- less common than above (500-3000 units); + - found in some analytical laboratories ( $<200$ units); $0-$ found in a few laboratories $(<50)$

VIII. SPARKS, THETA PINCH

DISCHARGES AND EXPLODING FILMS

Strictly speaking, these plasma sources are not "weakly ionized"; however, since they offer a potential competitive alternative to other plasmas discussed in this paper, a brief discussion is warranted. An pictorial synopsis of various configurations for pulsed electrical discharges that have been used for chemical analysis is provided in Fig. 24.
The transient-spark discharge (Fig. 24(a)) and dc arc, or transient arc discharge (Fig. 24(b)), have been used for many years for sampling and analysis of conducting samples. Excellent reviews are available [123], [124]. The most prevalent configuration for a spark discharge is one that utilizes two electrodes---one of which is the sample (the cathode), across which a high ac voltage is applied. The ac is usually pulsed at rates between a few hertz and several kilohertz such that the 


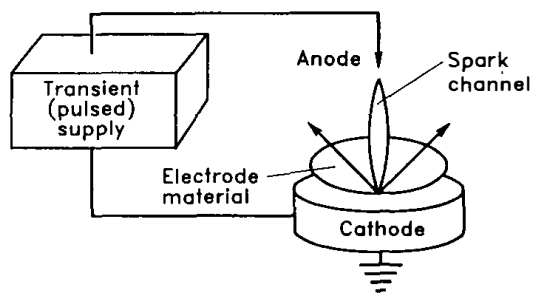

(a)

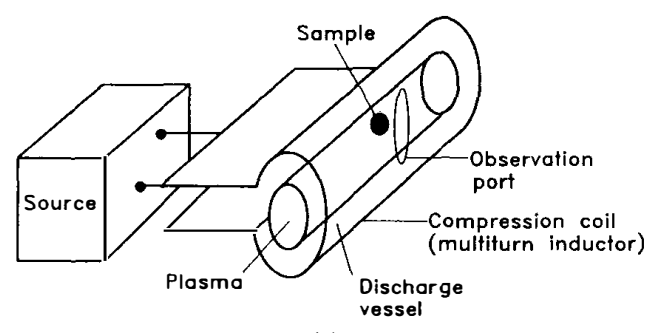

(c)

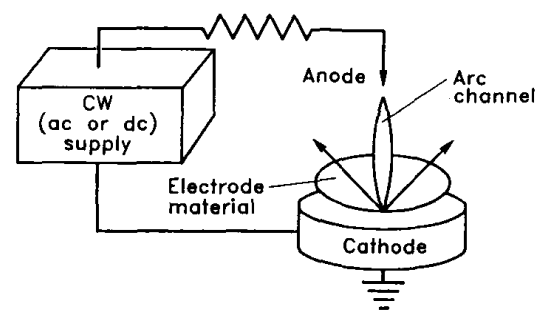

(b)

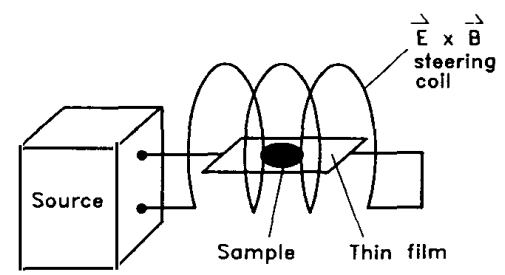

(d)

Fig. 24. Pictorial representation of: (a) spark, (b) ac or dc arc, (c) theta pinch, and (d) exploding thin film with $\mathrm{E} \times \mathrm{B}$ compression. $\mathrm{CW}=$ continuous wave power supply. Arrows indicate the propagation of the sampled material. (Reprinted with permission from [127].)

excitation waveforms are damped ac oscillations or rectified and filtered unidirectional transients. A characteristic of the excitation waveform is that a significant amount of energy is directed into the sample in a short period of time. The spark samples the electrodes both by sputtering and thermal evaporation. In common with glow discharges, the sampling efficiency of spark sources is dependent on the support gas and sample material.

Spark-source emission spectrometry has long been the traditional workhorse of the metals industry by providing fast sampling of conductors without the need of sample dissolution, and with a minimum of sample preparation and shaping. Spark-source mass spectrometry is also a method for obtaining the mass spectra of solids.

In recent years there has been some interest in using high-energy, pulsed plasma sources to combine the functions of sampling and excitation. The motivation for using these sources stems from the difficulty of sampling high-meltingpoint refractory compounds, ceramic insulators, and other chemically resistant nonconducting solids. In one approach to this problem, Sacks et al. have utilized exploding films. The sample is placed on a conducting thin film such as aluminum or gold that coats a nonconductor, and a transient current as high as several kiloamperes is discharged through the film [125]. A dense transient plasma is formed that vaporizes and excites the sample.

The plasma can be confined to a thin plane adjacent to the sample by placing the film in a magnetic field. Fig. 24(d) is a schematic of this type of configuration. White and Scheeline [126] have investigated the use of theta-pinch plasma discharges in which a diffuse glow discharge is formed around the sample, and the discharge is compressed into the sample using a pulsed magnetic field (Fig. 24(c)). They have reported that materials such as boron nitride and aluminum oxide can be atomized using this device. The plasma formed is very hot, and detection of emission from sample components is hampered by the intense continuum produced. Scheeline and Coleman have published a perspective on the use of these high-temperature transient discharges [127].

\section{EPILOGUE}

The intent of this paper was to introduce the use of weakly ionized plasmas for the sampling and analysis of materials. The focus on devices, rather than spectrochemical methods, was deliberate and, regretfully, many important details have been omitted. It is apparent that many different kinds of plasma source are utilized for chemical analysis, each with its own unique physical and analytical properties. Table III is a summary of relevant characteristics of some of the plasma sources used for analytical spectroscopy. Included in the table are the source, common method of application, approximate detection limit for that method, applicability for solid sampling, susceptibility to matrix effects, approximate cost (in \$1000), and the most common usage for the method. Obviously, this table is an oversimplification of reality, since it attempts to reduce the results of many tens-of-thousands of publications onto a single page, and in addition includes some biases of the authors. Nevertheless, this table will give some indication of the relative importance of the various sources discussed to the analytical industry.

The diversity of plasma sources used for chemical analysis is the result of the fact that no single plasma device satisfies all of the characteristics which would enable it to be designated as an "ideal source" for analytical spectrochemistry. Each has 
strengths and weaknesses. However, it should be noted that over the past few decades, plasma devices (in particular the ICP and DCP) have played a pivotal role in this field. Their chemical inertness, high temperature, abil ity to directly sample materials, and versatility have elevated them well above the competition, the chemical flame, and they are unlikely to be unseated in the near future. New and exciting developments in the field continue to be reported by many talented individuals who have provided us with powerful tools with which to probe and hence understand our environment.

\section{ACKNOWLEDGMENT}

The authors would like to thank C. Delheij-Joyce for assisting them in the preparation of this manuscript. M. W. Blades is grateful for research support, and P. Banks and C. Gill are grateful for postgraduate fellowships from the Natural Sciences and Engineering Research Council of Canada.

\section{REFERENCES}

[1] G. I. Babat, "Electrodeless discharges and some allied problems," $J$ Inst. Elect. Eng. (London), vol. 94, pp. 27-37, 1947.

[2] T.B, Reed, "Induction-coupled plasma torch," J. Appl. Phys., vol. 32. pp. $821-824,1961$.

[3] S. Greenfield, I. L. Jones, and C. T. Berry, "High pressure plasmas as spectroscopic emission sources," Analyst, vol. 89, pp. 713-720, 1965.

[4] R. H. Wendt and V. A. Fassel, "Induction-coupled plasma spectrometric excitation source," Anal. Chem., vol. 37, pp. 920-922, 1965.

[5] V. A. Fassel, "There must be an easier way: some reminiscences." Spectrochimica. Acta, vol. 40B, pp. 1281-1292, 1985.

[6] P. W. J. M. Boumans, Ed., Inductively Coupled Plasma Emission Spectroscopy. vols. I and II. New York: Wiley-Interscience, 1987.

[7] A. Montasser and D. W. Golightly, Eds., Inductively Coupled Plasmas in Analytical Spectrometry. New York: VCH Publishers, 1987.

[8] A. Montasser, "Mixed-gas, molecular gas, and helium inductively cou pled plasmas for analytical atomic spectroscopy: a critical review," Crit. Rev. Anal. Chem., vol. 18, pp. 45-103, 1987.

[9] R. F. Browner and A. F. Boorn, "Sample introduction: the Achilles' heel of atomic spectroscopy," Anal. Chem., vol. 56, pp. 786A-798A, 1984.

[10] _ "Sample introduction techniques for atomic spectroscopy," Anal Chem., vol. 56, pp. 875A-888A, 1984

[11] T. Nakahara, "Applications of hydride generation techniques in atomic absorption, atomic fluorescence, and plasma atomic emission spectroscopy," Prog. Anal. Atmos. Spectrosc., vol. 6, pp. 163-223, 1983.

[12] M. W. Blades, B. L. Caughlin, Z. H. Walker, and L. L. Burton, "Excitation, ionization, and spectral line emission in the inductively coupled plasma," Prog. Anal. Spectrosc., vol. 10, pp.57-109, 1987

[13] R. S. Houk, V. A. Fassel, G. D. Flesch, H. V. Svec, A. L. Gray, and C. E. Taylor, "Inductively coupled argon plasma as an ion source for mass spectrometric determination of trace elements," Anal. Chem., vol. 52, pp. 2283-2289, 1980.

[14] R. S. Houk, A. Montasser, and V. A. Fassel, "Mass spectra and ionization temperatures in an argon-nitrogen inductively coupled plasma," Appl. Spectrosc., vol. 37, pp. 425-428, 1983.

[15] D. F. Douglas, E. S. K. Quan, and R. G. Smith, "Elemental analysis with an atmospheric pressure plasma (MIP. ICP) quadrupole mass spectrometer system," Spectrochimica Acta, vol. 38B, pp. 39-50, 1983.

[16] A. R. Date and A. L. Gray, "Plasma source mass spectrometry using an inductively coupled plasma and a high resolution quadrupole mass filter," Analyst, vol. 106, pp. 1255-1267, 1981.

[17] D. F. Douglas and R. S. Houk, "Inductively coupled plasma mass spectrometry (ICP-MS)," Prog. Anal. Atmos. Spectrosc., vol. 8, p. 1 , 1985.

[18] A. L. Gray, "The ICP as an ion source--origins, achievements, and prospects," Spectrochimica. Acta, vol. 40B, pp. 1525-1537, 1985.

[19] G. M. Hieftje and G. H. Vickers, "Developments in plasma source mass spectrometry," Anal. Chim. Acta, vol. 216, pp. 1-24, 1989.

[20] M. A. Vaughn and G. Horlick, "Oxide, hydroxide, and doubly charged analyte species in ICP/MS," Appl. Spectrosc., vol. 40, pp. 434-445, 1986.

[21] M. A. Vaughn and G. Horlick, "Background spectral features in ICP/MS," Appl. Spectrosc., vol. 40, pp. 445-460, 1986.
[22] J. A. Olivares and R. S. Houk, "Suppression of analyte signal by various concomitant salts in inductively coupled plasma mass spectrometry," Anal. Chem., vol. 58, pp. 20-25, 1986.

[23] A. Montasser and V. A. Fassel, "Inductively coupled plasmas as atomization cells for atomic fluorescence spectrometry," Anal. Chem., vol. 48, pp. 1490-1499, 1976.

[24] D. R. Demers and C. D. Allemand, "Atomic fluorescence spectrometry with an inductively coupled plasma as atomization cell and pulsed hollow cathode lamps for excitation," Anal. Chem., vol. 53, pp. 1915-1921, 1981.

[25] M. Margoshes and B. F. Scribner, "The plasma jet as a spectroscopic source," Spectrochim. Acta, vol. 15, pp. 138-145, 1959.

[26] V. V. Korolev and E. E. Vainshtein, "Plasma generator as excitation source in spectroscopic analysis," 2 h. Anal. Khim., vol. 14, pp. 658-662, 1959.

[27] L. E. Owen, "Stable plasma jet for excitation of solutions," Appl. Spectrosc., vol. 15, pp. 150-152, 1961.

[28] B. F. Scribner and M. Margoshes, "Excitation of solutions in gasstabilized arc sources," in Proc. Int. IXth Coll. Spectroscopicum (Paris), 1962, pp. 309-324.

[29] W. G. Elliott, "Direct current argon plasma for analytical spectroscopy," Ph.D. diss., Univ. Massachusetts, 1987.

[30] S. E. Valente and W. G. Schrenk, "The design and some emission characteristics of an economical dc arc plasmajet excitation source for solution analysis," Appl. Spectrosc., vol. 24, pp. 197-205, 1970.

[31] M. Marinkovic and T. J. Vickers, "Free atom production in a stabilized dc arc device for atomic absorption spectrometry," Appl. Spectrosc., vol. 25 , pp. $319-324,1971$

[32] W. E. Rippetoe, E. R. Johnson, and T. J. Vickers, "Characterization of the plume of a direct current plasma arc for emission spectrometric analysis," Anal. Chem., vol. 47, pp. 436-440, 1975.

[33] C. D. Keirs and T. J. Vickers, "Some dc plasma arcs for elemental analysis," Appl. Spectrosc., vol. 31, pp. 273-283, 1977.

[34] G. N. Coleman, W. P. Braun, and A. M. Allen, "Characterization of an improved dc plasma excitation source," Appl Spectrosc., vol. 34, pp. 24-30, 1980.

[35] A. T. Zander and M. H. Miller, "Electron density spatial profiles of the DCP source," Spectrochim. Acta, vol. 40B, pp. 1023-1037, 1985.

[36] M. H. Miller, "Letter to the editor," Spectrochim. Acta, vol. 38B, pp. 1265-1266, 1983.

[37] M. W. Blades and N. Lee. "A spatial study of electron density and analyte emission in a dc argon plasma," Spectrochim. Acta, vol. 39B, pp. 879-890, 1984.

[38] M. H. Miller, D. Eastwood, and M. S. Hendrick, "Excitation of analytes and enhancement of emission intensities in a dc plasma jet: a critical review leading to proposed mechanistic models," Spectrochim. Acta, vol. $39 \mathrm{~B}$, pp. $13-56,1984$

[39] R. J. Decker, "Some analytic characteristics of the three electrode dc argon plasma source for optical emission spectrometry," Spectrochim. Acta, vol. 35B, pp. 19-31, 1980.

[40] C. LeBlanc and M. W. Blades, "Spatially resolved laser-induced fluorescence studies on a three-electrode direct current plasma," J. Anal. Atom. Spectrom., vol. 5, pp. 99-107, 1990.

[41] A. T. Zander and G. M. Hieftje, "Microwave-supported discharges," Appl. Spectrosc., vol. 35, pp. 357-371, 1981

[42] J. P. Matousek, B. J. Orr, and M. Selby, "Microwave-induced plasmas: implementation and application," Prog. Anal. Spectrosc., vol. 7, pp. 275-314, 1984.

[43] C. I. M. Beenakker, "A cavity for microwave-induced plasma operated in helium and argon at atmospheric pressure," Spectrochim. Acta, vol. 31B, pp. 483-486, 1976

[44] S. R. Goode and K. W. Baughman, "A review of instrumentation used to generate microwave-induced plasmas," Appl. Spectrosc., vol. 38, pp. 755-763, 1984.

[45] M. Moisan, C. Beaudry, and P. Leprince, "A new HF device for the production of long plasma columns at high electron density," Phys. Lett., vol. 50, pp. 125-126. 1974.

[46] J. Hubert, M. Moisan, and A. Ricard, "A new microwave plasma at atmospheric pressure," Spectrochim. Acta, vol. 34B, pp. 1-10, 1979.

[47] M. Moisan and Z. Zakrzewski, "Plasma sources based on the propagation of electromagnetic surface waves," J. Phys. D: Appl. Phys., vol. 24, 1025-1048, 1991

[48] A. J. McCormack, S. C. Tong, and W. D. Cooke, "Sensitive selective gas chromatography detector based on emission spectrometry of organic compounds," Anal. Chem., vol. 37, pp. 1470-1476, 1965.

[49] C. A. Bache and D. J. Lisk, "Determination of organophosphorus insecticide residues using the emission spectrometric detector," Anal. Chem., vol. 37, pp. 1477-1480, 1965. 
[50] F. E. Lichte and R. K. Skogerboe, "Analysis of solution samples by microwave-induced plasma excitation," Anal. Chem., vol. 45, pp. $399-401,1973$.

[51] D. L. Hass and J. A. Caruso, "Characterization of a moderate-power microwave-induced plasma for direct solution nebulization of metal ions," Anal. Chem., vol. 56, pp. 2014-2019, 1984.

[52] K. G. Michlewicz, J. J. Urh, and J. W. Carnahan, "A microwaveinduced plasma system for the maintenance of moderate power plasmas of helium, argon, nitrogen and air," Spectrochim. Acta, vol. 40B, pp. $493-499,1985$.

[53] C. I. M. Beenakker. "Evaluation of a microwave-induced plasma in helium at atmospheric pressure as an element-elective detector for gas chromatography," Spectrochim. Acta, vol. 32B, pp. 173-187, 1977.

[54] B. D. Quimby and J. J. Sullivan, "Evaluation of a microwave cavity, discharge tube, and gas flow system for combined gas chromatography-atomic emission detection," Anal. Chem., vol. 62, pp. 1027-1034, 1990.

[55] F. Paschen, "Bohrs heliumlinien," Ann. Phys., vol. 50, pp. 901-940, 1916.

[56] W. Grimm, "Eine neue glimmentladungslampe für die optische emissions-spektralanalyse," Spectrochim. Acta, vol. 23B, pp. 443-454, 1968.

[57] H. Falk, E. Hoffman, and Ch. Lüdke, "FANES (Furnace Atomic Nonthermal Excitation Spectrometry)--a new emission technique with high detection power," Spectrochim. Acta, vol. 36B, pp. 767-771, 1981.

[58] J. A. C. Broekaert, "State of the art of glow discharge lamp spectrometry," J. Anal. At. Spectrom., vol. 2, pp. 537-543, 1987.

[59] M. E. Pillow, "A critical review of spectral and related physical properties of the hollow cathode discharge," Spectrochim. Acta, vol. 36B, pp. 821-843, 1981.

[60] P. W. J. M. Boumans, "Studies of sputtering in a glow discharge for spectrochemical analysis," Anal. Chem., vol. 44, pp. 1219-1228, 1972.

[61] S. Caroli, "Low-pressure discharges: fundamental and applicative aspects," J. Anal. Atmos. Spectrom., vol. 2, pp. 661-680, 1987.

[62] R. A. Kruger, R. M. Bombelka, and K. Laqua, "Applications of the Grimm magnetic field glow-discharge source to the analysis of mild and alloyed steel," Spectrochim. Acta, vol. 35B, pp. 589-599, 1980.

[63] L. McCaig, N. Sesi, and R. Sacks, "Pressure sensitivity of emission intensities and plasma voltage for a planar magnetron glow discharge," Appl. Spectrosc., vol. 44, pp. 1176-1182, 1990.

[64] N. P. Ferriera, J. A. Strauss, and H. G. C. Human, "Developments in glow discharge emission spectrometry," Spectrochim. Acta, vol. 38B, pp. 899-911, 1983 .

[65] H. Falk, Improved Hollow Cathode Lamps for Atomic Spectroscopy, S. Caroli, Ed. New York: Wiley, 1985, p. 74

[66] N. E. Ballou, D. L. Styris, and J. M. Harnly, "Hollow-anode plasma excitation source for atomic emission spectrometry," J. Anal. Atmos. Spectrom., vol. 3, pp. 1141-1143, 1988.

[67] J. M. Harnly, D. L. Styris, and N. E. Ballou, "Furnace atomic nonthermal excitation spectrometry with the furnace as a hollow anode," $J$. Anal. Atmos. Spectrom., vol. 5, pp. 139-144, 1990.

[68] P. G. Riby, J. M. Harnly, and D. L. Styris, "The determination of boron by hollow anode furnace atomization non-thermal excitation spectrometry," presented at the 1991 Pittsburg Conf. and Exhibition on Analytical Chemistry and Applied Spectroscopy, Chicago, IL, Mar. $3-8,1991$

[69] B. L. Bentz and W. W. Harrison, "Glow discharge mass spectrometry," Prog. Anal. Spectrosc., vol. 11, pp. 53-110, 1988.

[70] A. E. Bernhard, "Atomic absorption spectrometry using sputtering atomization of solid samples," Spectroscopy, vol. 2, pp. 38-40, 1987.

[71] P. R. Banks and M. W. Blades, "Atomic emission spectroscopy using a jet-assisted glow discharge source," Spectrochim. Acta, vol. 44B, pp. $1117-1124,1989$.

[72] B. M. Gatehouse and A. Walsh, "Analysis of metallic samples by atomic absorption spectroscopy," Spectrochim. Acta, vol. 16, pp. 602-604, 1960.

[73] D. C. MacDonald, "Use of internal standards for atomic absorption spectrometric analyses of samples atomized by sputtering," Anal. Chem., vol. 49, pp. 1336-1339, 1977.

[74] H. G. C. Human, N. P. Ferreira, R. A. Kruger, and L. R. P. Butler, "Analysis of metals using a glow-discharge source with a fluorescent atomic vapor as spectral-line isolator," Analyst, vol. 103, pp. 469-474, 1978.

[75] H. Bubert, "Atomic fluorescence spectrometry with a Grimm-type glow discharge lamp," Spectrochim. Acta, vol. 39B, pp. 1377-1387, 1984

[76] B. L. Bentz, C. G. Bruhn, and W. W. Harrison, "Sampling a hollow cathode discharge with a quadrupole mass filter," Int. J. Mass Spectrom. Ion Phys., vol. 28, pp. 409-425, 1978.
[77] W. W. Harrison, "Glow discharge mass spectrometry: a current assessment," J. Anal. Atmos. Spectrom., vol. 3, pp. 867-872, 1988.

[78] D. C. Duckworth and R. K. Marcus, "Radio frequency powered glow discharge atomization/ionization source for solids mass spectrometry," Anal. Chem., vol. 61, pp. 1879-1886, 1989.

[79] "GDL Issue (part I)--analytical atomic spectrometry: use and exploration of low pressure discharges," Spectrochimica Acta, vol. 46B pp. 111-314, 1991; see also, "GDL Issue (part II)--analytical atomic spectrometry: use and exploration of low pressure discharges," Spectrochimica Acta, vol. 46B, pp. 457-545, 1991

[80] G. Cristescu and R. Grigorovici, "Optical temperature determinations in the high-frequency "torch" discharge," Naturwissenschaften, vol. 29, pp. 571-572, 1941.

[81] K. A. Egorova, "Use of a high-frequency electrodeless discharge in the analysis of solutions," Zh. Prikl. Spektrosk., vol. 6, pp. 12-14, 1967.

[82] A. V. Zvyagintsev, R. V. Mitin, and K. K. Pryadkin, "Electrodeless capacitive arc," Sov. Phys.-Tech. Phys., vol. 20, pp. 177-181, 1975.

[83] N. I. Gonchar, A. V. Zvyagintsev, R. V. Mitin, and K. K. Pryadkin, "Electrodeless plasma generator (plasmatron) with capacitive arc discharge," Sov. Phys.-Tech. Phys., vol. 20, pp. 407-408, 1975.

[84] B. Platzer, E. Leitner, G. Knapp, A. Schalk, and A. Grillo, "An elementspecific gc detector," Amer. Lab., pp. 12-17, Aug. 1990.

[85] W. G. Elliott, "Capacitively coupled plasma device," U.S. Patent 4479075,1984

[86] R. J. Winslow, Ph.D. diss., Univ. Massachusetts, 1980

[87] D. C. Liang and M. W. Blades, "Atmospheric pressure capacitively coupled plasma atomizer for atomic absorption spectrometry," Anal. Chem., vol. 60,.pp. 27-31, 1988 .

[88] D. Huang, D. C. Liang, and M. W. Blades, "Capacitively coupled plasma detector for gas chromatography," J. Anal. Atmos. Spectrom., vol. 4, pp. 789-791, 1989

[89] D. Huang and M. W. Blades, "Evaluation of a $13.56 \mathrm{MHz}$ capacitively coupled plasma as a detector for gas chromatographic determination of organotin compounds," J. Anal. Atmos. Spectrom., vol. 6, pp. 215-219, 1991

[90] D. C. Liang and M. W. Blades, "An atmospheric pressure capacitively coupled plasma formed inside a graphite furnace as a source for atomic emission spectroscopy," Spectrochim. Acta, vol. 44B, pp. 1059-1063, 1989.

[91] R. E. Sturgeon, S. N. Willie, and V. T. Luong, "Characteristic temperatures in a FAPES source," Spectrochim. Acta, vol. 46B, pp. 1021-1031, 1991.

[92] T. D. Hettipathirana and M. W. Blades, "Furnace atomization plasma excitation spectroscopy: spectral, spatial, and temporal characteristics," Spectrochim. Acta., to be published.

[93] R. E. Sturgeon, S. N. Willie, V. T. Luong, S. S. Berman, and J. G. Dunn, "Furnace atomization plasma emission spectrometry," J. Anal. Atmos. Spectrosc., vol. 4, pp. 669-672, 1989.

[94] D. L. Smith, D. C. Liang, D. Steel, and M. W. Blades, "Analytical characteristics of furnace atomization plasma excitation spectrometry," Spectrochim. Acta, vol. 45B, pp. 493-498, 1990.

[95] R. E. Sturgeon, S. N. Willie, V. T. Luong, and S. S. Berman, "Figures of merit for furnace atomization plasma emission spectrometry," Anal. Chem., vol. 62, pp. 2370-2376, 1990.

[96] S.-K. Chan, H. Tan, and A. Montaser, "Tandem helium plasma spectrometry with a capacitively coupled discharge formed above a helium ICP," Appl. Spectrosc. vol. 43, pp. 92-95, 1989.

[97] A. P. D'Silva, G. W. Rich, and V. A. Fassel, "Atmospheric pressure active nitrogen (APAN)--a new source for analytical spectroscopy," Appl. Spectrosc., vol. 34, pp. 578-584, 1980.

[98] G. W. Rice, A. P. D'Silva, and V. A. Fassel, "A new He dischargeafterglow and its application as a gas chromatographic detector," Spectrochim. Acta, vol. 40B, pp. 1573-1584, 1985.

[99] R. J. Skelton, Jr., K. E. Markides, M. L. Lee, and P. B Farnsworth, "Characterization of near-infrared atomic emission from a radio-frequency plasma for selective detection in capillary gas chromatography," Appl. Spectrosc., vol. 44, pp. 853-857, 1990

[100] D. Zamzow and A. P. D'Silva, "The effect of neon and argon additions on improving selectivities in the helium afterglow discharge detector," Appl. Spectrosc., vol. 44, pp. 1074-1079, 1990.

[101] J. D. Cobine and D. A. Wilbur, "The electronic torch and related high frequency phenomena," J. Appl. Phys., vol. 22, pp. 835-841, 1951.

[102] W. Schmidt, in Elektron. Rundschau., vol. 13, p. 404, 1959.

[103] S. Hanaamura, B. W. Smith, and J. D. Winefordner, "A single electrode atmospheric pressure microwave discharge system for elemental analysis," Can. J. Spectrosc., vol. 29, pp. 13-18, 1984.

[104] J. D. Hwang, W. Masamba, B. W. Smith, and J. D. Winefordner, "Development of high power, capacitatively coupled microwave $\mathrm{He}$ - 
lium plasma for atomic emission spectroscopy (CMP-AES)," Can. J. Spectrosc., vol. 33, pp. 156-160, 1988.

[105] B. M. Patel, E. Heithmar, and J. D. Winefordner, "Tubular electrode torch for capacitatively coupled Helium microwave plasma as a spectrochemical excitation source," Anal. Chem., vol. 59, pp. 2374--2377, 1987.

[106] M. Huang, D. S. Hanselman, Q. Jin, and G. M. Hieftje, "Non-thermal features of atmospheric-pressure argon and helium microwave-induce plasmas observed by laser-light Thompson scattering and Raleigh scattering," Spectrochim. Acta., vol. 45B, pp. 1339-1352, 1990.

[107] P. W. J. M. Boumans, F. J. de Boer, F. J. Dahmen, H. Hoelzel, and A. Meier, "A comparative investigation of some analytical performance characteristics of a inductively-coupled radio frequency plasma and a capacitively-coupled microwave plasma for solution analysis by emission spectrometry," Spectrochim. Acta, vol. 30B, pp. 449-469, 1975.

[108] T. H. Maiman, "Optical and microwave-optical experiments in Ruby," Phys. Rev. Lett., vol. 4, pp. 564-566, 1960.

[109] F. Brech and L. Cross, "Optical micromission stimulated by a Ruby laser," Appl. Spectrosc., vol. 16, p. 59, 1962

[110] L. J. Radziemski and D. A. Cremers, Eds., Laser Induced Plasmas and Applications. New York: Marcel Dekker, 1989.

[111] L. Moenke-Blankenburg, "Laser micro analysis," Prog. Anal. Spectrosc., vol. 9, pp. 335-427, 1986

[112] R. S. Adrain and J. Watson, "Laser microspectral analysis: a review of principles and applications," J. Phys. D: Appl. Phys., vol. 17, pp. 1915-1940, 1984.

[113] N. Fürstenau, F. Hillenkamp, and R. Nitsche, "Laser-induced positive and negative molecular ions from thin carbon foils," Int. J. Mass Spectrom. Ion Phys., vol. 31, pp. 85-91, 1979.

[114] N. Fürstenau and F. Hillenkamp, "Laser-induced cluster-ions from thin foils of metals and semiconductors," Int. J. Mass Spectrom. Ion Phys., vol. 37, pp. 135-151, 1981

[115] P. Hughes, Plasmas and Laser Light. Bristol, MA: Adam Hilger, 1975.

[116] O. N. Krokhin, "Generation of high temperature vapor and plasmas by laser radiation," in Laser Handbook, vol. 2, F. T. Arecchi and E. O. Schulz du Bois, Eds. Amsterdam: North Holland, 1972, pp. 1371-1407.

[117] C. DeMichelis, "Laser interaction with solids-a bibliographical review," IEEE J. Quant. Electron., vol. QE-6, pp. 630-641, 1970.

[118] J. F. Ready, "Effects due to absorption of laser radiation," Appl. Phys., vol. 36, pp. 462--468, 1965.

[119] J. F. Ready, Effects of High Power Laser Radiation. New York: Academic, 1971.

[120] J. F. Ready, "Industrial Applications of Lasers. Toronto, ON, Can.: Academic, 1978

[121] E. R. Denoyer, K. J. Fredeen, and J. W. Hager, "Laser solid sampling for inductively coupled plasma mass spectrometry," Anal. Chem., vol. 63, pp. 445A--457A, 1991.

[122] D. M. Lubman, Ed., Lasers and Mass Spectrometry. New York: Oxford Univ. Press, 1990.

[123] J. P. Walters, "Spark discharge: applications to multielement spectrochemical analysis," Science, vol. 198, pp. 787-797, 1977.

[124] A. Scheeline, "High voltage discharges: diagnostics and opportunities," Prog. Anal. Atmos. Spectrosc., vol. 7, pp. 21-66, 1984

[125] R. D. Sacks, J. M. Goldberg, R. J. Collins, and S. Y. Suh, "Exploding conductors as atomization cells and excitation sources for atomic spectroscopy," Prog. Anal. Atmos. Spectrosc., vol. 5, pp. 111-151, 1982.

[126] J. S. White and A. Scheeline, "Sampling and excitation of refractory solids with a theta pinch discharge designed as an atomic emission source," Anal. Chem., vol. 59, pp. 305-309, 1987.

[127] A. Scheeline and D. M. Coleman, "Direct solids elemental analysis: pulsed plasma sources," Anal. Chem., vol. 59, pp. 1185A-1196A, 1985.

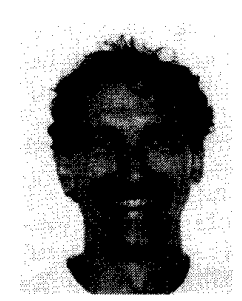

Michael W. Blades was born in 1951 in Nova Scotia, Canada. In 1971 he obtained the diploma in electronic engineering technology from the Nova Scotia Institute of Technology and worked as an Electronic Technician at the Defence Research Establishment-Atlantic in Dartmouth, NS. He received the undergraduate degree from St. Marys University in 1975, and the Ph.D. degree from the University of Alberta in 1980 under the supervision of Dr. G. Horlick. He subsequently went to Indiana University to work as a Postdoctoral Research Associate in the laboratory of Dr. G. Hieftje (1980-1981).
He is currently a full Professor in the Department of Chemistry at the University of British Columbia, where he has been since 1981. His current research interests are in the areas of plasma spectroscopy, in particular, the development of new plasma sources and the characterization of excitation conditions in plasmas; laser spectroscopy; and ion-storage mass spectrometry. $\mathrm{He}$ is currently an Editor for Spectrochimica Acta Reviews and is on the editorial board of Spectrochimica Acta B.

Professor Blades is the recipient of the 1987 Canadian Society for Chemistry McBryde Medal, awarded annually to a "young" scientist "in recognition of a significant achievement in pure or applied analytical chemistry," and a University of British Columbia Killiam Research Prize (1988-1989).

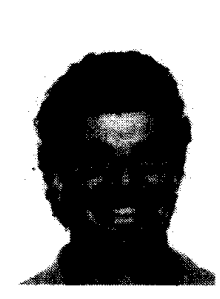

Peter Banks was born in Bombay, India, in 1959 and emigrated to Canada in 1965 . He is a Graduate Student in analytical chemistry, nearing completion of the Ph.D. degree in the laboratories of Dr. M. Blades at the University of British Columbia. His thesis concerns the use of directed support gas flows in glow discharges to impede sputtered atom redeposition. His work is presently supported by an NSERC Postgraduate Scholarship. He received the B.Sc. degree (First Class) in chemistry in 1986 from the University of British Columbia. His undergraduate thesis involved the synthesis and magnetic properties of various inorganic polymers. Before enrolling in graduate school, he was employed by Chemex Labs, Inc., North Vancouver, for the assay of geological and related materials by ICP-OES and ICP-AFS.

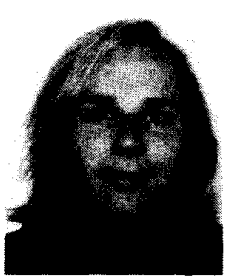

Chris Gill is a Graduate Student in analytical chemistry at the University of British Columbia (UBC). He was born in 1966 in Nova Scotia, Canada, and received the B.Sc.H. degree from Acadia University in 1989. His undergraduate thesis involved the analytical characterization of exoskeletal lipids and hydrocarbons of marine crustacea. Now entering the third year of the Ph.D. degree program, his research interests include ion trap mass spectrometry and laser applications in analytical chemistry.

Among the awards he received during his undergraduate career were two NSERC summer research fellowships, the E.P. Linton Award, the Acadia University Medal of Excellence in Chemistry, and the CSC Student Merit Award. In addition, he received a postgraduate NSERC award, which he chose to use for studies at UBC, and is the recipient of the Federation of Analytical Chemistry and Spectroscopy Societies-1991 Thomas Hirschfeld Award.

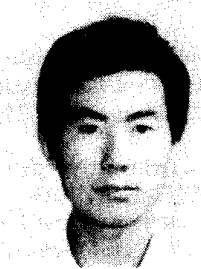

Degui Huang received the B.S. degree in chemistry in 1982 from Wuhan University of Geology, Wuhan, China, where after graduation he worked as an Assistant Researcher in the Central Laboratory through 1988. Having worked with Prof. M.W. Blades for a year as a Visiting Scientist, he started his graduate study in the Department of Chemistry a the University of British Columbia in 1989. In 1991 he received the M.S. degree for his thesis, "The Development of a Capacitively Coupled Plasma as a Gas Chromatographic Detector." 


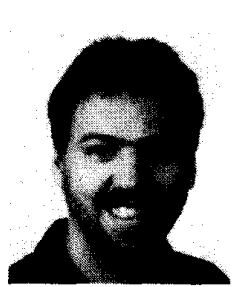

Charles Le Blanc is a Graduate Student in analytical chemistry at the University of British Columbia (UBC). Bom in Nova Scotia, he received the B.Sc.H. degree in 1986 from Acadia University, where his thesis dealt with the development of an analytical pyrolysis gas chromatography procedure for the analysis of chitin and chitosans derived from the exoskeletons of marine crustaceons. He received the M.Sc. degree in analytical chemistry (fundamental studies of a dc plasma) in 1990 from UBC, and was employed by Bondar-Clegg and Company Ltd. during 1990-1991. He is currently in the Ph.D. degree program at UBC, where he is carrying out research on novel plasma sources.

Among the awards he received during his undergraduate career were the

Crowell Entrance Scholarship and the Award of Merit for Highest Standing in his graduate class. He is also the recipient of the Walter C. Sumner Award.

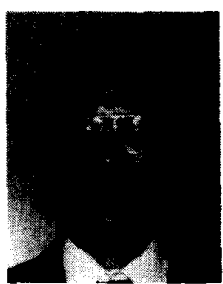

Dong Liang graduated from the Guangzhou Engineering College in 1966 and spent the next 10 years as an Analytical Chemist at the Guangzhou Chemical Reagent Factory. In 1976 he became a Research Chemist at the South China Sea Institute of Oceanology. In 1984 he went to Canada and obtained the M.Sc. degree in analytical chemistry in 1986 from Dalhousie University (Halifax, NS) under Dr. R. Stevens. He continued his studies at the University of British Columbia under Prof. M.W. Blades and received the $\mathrm{Ph} . \mathrm{D}$. degree in 1990. His thesis involved the development of capacitively coupled plasmas for analytical spectroscopy.

After receiving his doctorate degree, he formed a company, Aurora Instruments Ltd., for the commercial development of analytical instrumentation. 